IZA DP No. 8315

The Public Sector Wage Premium in Spain:

Evidence from Longitudinal Administrative Data

Laura Hospido

Enrique Moral-Benito

July 2014 


\title{
The Public Sector Wage Premium in Spain: Evidence from Longitudinal Administrative Data
}

\author{
Laura Hospido \\ Banco de España \\ and IZA \\ Enrique Moral-Benito
}

Banco de España

Discussion Paper No. 8315

July 2014

IZA

P.O. Box 7240

53072 Bonn

Germany

Phone: +49-228-3894-0
Fax: +49-228-3894-180
E-mail: iza@iza.org

Any opinions expressed here are those of the author(s) and not those of IZA. Research published in this series may include views on policy, but the institute itself takes no institutional policy positions. The IZA research network is committed to the IZA Guiding Principles of Research Integrity.

The Institute for the Study of Labor (IZA) in Bonn is a local and virtual international research center and a place of communication between science, politics and business. IZA is an independent nonprofit organization supported by Deutsche Post Foundation. The center is associated with the University of Bonn and offers a stimulating research environment through its international network, workshops and conferences, data service, project support, research visits and doctoral program. IZA engages in (i) original and internationally competitive research in all fields of labor economics, (ii) development of policy concepts, and (iii) dissemination of research results and concepts to the interested public.

IZA Discussion Papers often represent preliminary work and are circulated to encourage discussion. Citation of such a paper should account for its provisional character. A revised version may be available directly from the author. 


\section{ABSTRACT \\ The Public Sector Wage Premium in Spain: Evidence from Longitudinal Administrative Data*}

This paper studies the public sector wage gap in Spain, by gender, skill level and type of contract, using recent administrative data from tax records. We estimate wage distributions in the presence of covariates separately for men and women in the public and in the private sectors, and we take advantage of the longitudinal structure of the data to control for selection. We find a positive public wage premium for men and women even after accounting for characteristics and endogenous selection; the observed average gap in hourly wages of 35 log points is reduced to 20 when accounting for observed characteristics, and to 10 once endogenous selection is also taken into consideration. We also find substantial variation in the public premium along the wage distribution once observed characteristics are accounted for. This variation, however, is offset by opposite patterns of selection into the public sector: while we observe positive selection into the public sector at the bottom of the wage distribution, workers at the top of the distribution select negatively into the public sector.

JEL Classification: $\quad$ C21, C23, J31, J45

Keywords: public sector wage gap, quantile regression, wage distribution, panel data

Corresponding author:

Laura Hospido

Bank of Spain

Research Division

DG Economics, Statistics, and Research

Alcalá 48

28014 Madrid

Spain

E-mail: laura.hospido@bde.es

\footnotetext{
* We thank Samuel Bentolila, Sara de la Rica, Blaise Melly, and Ildefonso Méndez for useful comments. We also thank seminar participants at the Bank of Spain, the IEB at the Universitat de Barcelona, the Universitat de les Illes Balears, the SAEe Meetings in Vigo, the ESPE Conference in Aarhus, the Jornadas de Economía Laboral in Madrid, and the EEA-ESEM meetings in Gothenburg. All remaining errors are our own. The opinions and analyses are the responsibility of the authors and, therefore, do not necessarily coincide with those of the Banco de España or the Eurosystem. First draft: June 10, 2012.
} 


\section{Introduction}

In 2012, more than $15 \%$ of the labor force received their wage from the public sector and compensation of employees represented around 30\% of Spanish public consumption expenditures. In order to ensure fiscal sustainability under pressure from financial markets, the Spanish Government has undertaken huge fiscal consolidation efforts, and - in particular - the size of the public sector wage bill has been under scrutiny. Indeed, several measures aiming at reducing this public sector wage bill have been already implemented. ${ }^{1}$ Under these circumstances, a deep understanding of the public-private wage gap and its distribution seems of paramount importance. $^{2}$

Public and private sectors workers can be paid differently because of several reasons: (i) the monopolistic power of governments in the provision of public services results in non-competitive wage settlements (Reder, 1975); (ii) the public sector might have different objectives from those of the private sector, for instance, vote maximization rather than profit maximization; (iii) the wage setting environment substantially differs between both sectors, for example, union density is often higher in the public sector; (iv) productivity-enhancing characteristics of employees such as education or experience might be different between both sectors. In this paper we argue that the room for cutting public sector wages should be based on the public wage gap due to reasons (i)-(iii) so that we focus on the analysis of the public wage gap not explained by productivity-related characteristics of employees in the two sectors.

There exists an extensive literature analyzing the public - private wage gap based on average figures for different countries including Spain. However, the average public sector wage premium only provides an incomplete picture of the whole distribution. Therefore, there is also a more recent literature analyzing the whole distribution of the public-private wage gap based on quantile methods (see section 2 for an overview). We embed our paper into this strand of the literature. In particular, we analyze the distribution of the public-private wage gap in Spain using recently developed methods for estimating counterfactual distributions (i.e. Chernozhukov, Fernandez-Val and Melly, 2013; hereinafter, CFVM) combined with fixed effects quantile regressions (Canay, 2011) to account for endogenous selection into the public sector.

For that purpose we use a dataset based on tax records which allows us to overcome a potential drawback of previous empirical studies about the public-private wage gap based on survey data. To the best of our knowledge, all those studies are based on databases in which responses are provided by individual workers (e.g. the German Socio-Economic Panel, the European Community Household Panel, or the Wage Structure Survey in the Spanish case). Concerns about response errors in survey data and their implications for economic analysis date back to the fifties (e.g. Cohen and Lipstein, 1954; Miller and Paley, 1958). For instance,

\footnotetext{
${ }^{1}$ In 2010 and 2012 the Spanish Government approved cuts in the nominal wages of public employees, and in 2011 and 2013 the decision was to freeze those wages.

${ }^{2}$ Furthermore, as a side-effect, cuts in public sector wages might induce reductions in private wages with the subsequent gains in terms of competitiveness (see Lamo et al., 2012).
} 
using two unique matched worker-employer data files, Mellow and Sider (1983) find that almost one-half of workers surveyed indicate a different detailed occupation than is reported by their employer. Zweimuller (1992) concludes that sample selectivity due to interviewees' refusal to answer to the survey-questionnaire is a significant problem, even of larger importance than the selectivity bias due to non-participation in the labor market. ${ }^{3}$ Regarding the quality of survey measures of income, several studies (e.g. Herriot and Spiers, 1980; Gottschalk et al., 2008; Gottschalk and Huynh, 2010) use earnings reports from survey data (e.g. PSID or CPS) matched to tax records and find substantial evidence that measurement error in self-reported earnings is important and not classical. Moreover, an additional concern is that reporting biases may follow different patterns between public and private sector workers; while income sources for public sector employees are clearly determined and unambiguously-established, uncertainty surrounding income in the private sector is more important due to, for instance, bonuses or extra hours.

In this paper, we use recently released social security data for Spain. Social security records have several advantages compared to the survey-based datasets that have been previously used. These include large sample sizes, complete coverage of the part of the population that is affiliated to the social security administration, and accurate earnings measurements. We focus on the period 2005-2012, for which the social security dataset has a proper longitudinal design (before 2005 the information is retrospective). In addition, in that period, annual income information from tax records are available for the same individuals as in the social security dataset. Contrary to the social security measure of labor earnings that is top- (and bottom-) coded, tax records are not subject to censoring, making them suitable to perform our study. On the other hand, the social security dataset do not record hours of work. To overcome this drawback, we match our dataset with information on hours from the Spanish Labor Force Survey.

In order to analyze the public-private wage gap in detail, we estimate wage distributions in the presence of covariates separately for men and women in the public sector and in the private sector. Moreover, we take advantage of the longitudinal structure of the data to control for endogenous selection into the public sector. Armed with these estimates, we decompose the public sector wage gap along the wage distribution and isolate the part due to differences in the remunerations of both observable and time-invariant unobserved characteristics.

We find a positive public wage premium for men and women even after accounting for characteristics and endogenous selection; the observed average gap in hourly wages, of around 35\%, is reduced to $20 \%$ when accounting for observed characteristics, and to $10 \%$ once endogenous selection is also taken into consideration. We also find substantial variation in the public premium along the wage distribution once observed characteristics are accounted for; for instance, the public gap for high-skilled men is $18 \%$ at the $10^{\text {th }}$ percentile and $-21 \%$ at the $90^{\text {th }}$ percentile. However, this variation is partially offset by different patterns of selection into the public sector,

\footnotetext{
${ }^{3}$ For more details on this issue see also Griliches et al. (1978), Atkinson and Micklewright (1983), or Groves (2006)
} 
which generate a higher compression of the public wage distribution. Indeed, while we generally observe positive selection into the public sector, high-skilled workers at the top of the distribution select negatively; this negative selection at the top might reflect the inability of the public sector to retain the most skilled workers due to the absence of performance-based mechanisms.

The rest of the paper is organized as follows. We start by summarizing the relevant literature in Section 2. We describe the data in Section 3. Then we sequentially explain our methodological approach and discuss our results for the average public sector wage gap in Section 4, the wage gap over the distribution in Section 5, and for those gaps taking into account the role of unobservables (i.e. endogenous selection) in Section 6. Lastly, Section 7 concludes.

\section{Related Literature}

Several studies have already addressed the issue of the public - private wage gap in different countries. Some examples based on average gaps are Smith (1976) or Borjas (2002) for the United States, Dustmann and Van Soest (1997) for Germany, Panizza and Qiang (2005) for Latin American countries, Anghel et al. (2011) for OECD countries, De Castro et al. (2013) for the European Union countries, and Lassibille (1998), or García-Pérez and Jimeno (2007) for Spain. This strand of the literature has reached consensus in the following findings: (i) the public premium is positive for low-skilled male workers but negative for the high-skilled ones when observable characteristics are accounted for; (ii) the public premium remains positive for females even after controlling for individual characteristics; and (iii) the distribution of wages is more compressed in the public sector. ${ }^{4}$

Since the public sector apparently compresses the distribution of wages, the mean public sector wage premium only provides an incomplete picture of the whole distribution. In response to this concern, several authors, including ourselves, apply quantile regression (QR) methods to analyze the whole distribution of the public-private wage gap.

Mueller (1998) used QR to estimate the size of the public sector wage premium for Canada. He found that public sector pay differentials tend to be highest for federal government employees, females and individuals at the lower tail of the wage distribution. Similar results were reported by Cai and Liu (2011) for Australia. Utilizing QR analysis, they show that the public sector pay premium declines at the higher spectrum of the wage distribution and becomes negative for male workers at the top half of the conditional wage distribution. Melly (2005) measures and decomposes the differences in earnings distributions between public and private sector employees in Germany for the years 1984-2001. Results suggest that conditional wages are higher in the public sector for women but lower for men; the "premium" is highest at the lower end of the distribution and then monotonically decreases by moving up the wage distribution. His findings are stable over the '80s and the '90s. Papapetrou (2006) using microdata from the European Community Household Panel Survey (ECHP) for Greece reports that average earnings are

\footnotetext{
${ }^{4}$ See Gregory and Borland (1999) for a survey of this literature.
} 
higher in the public sector than in the private sector and employees in the public sector at the lower end of the wage distribution earn a higher wage gap compared with their counterparts in the private sector, but this gap decreases at higher quantiles. Furthermore, QR estimation reveals that earnings differentials at the lower end of the wage distribution cannot be attributed to individual characteristics whereas at the highest quantiles pay differentials reflect differences in the employee's endowment. Boyle et al. (2004) report wage premia for public sector workers, greater for low-paid workers and smaller for public sector workers at the top of the earnings distribution using microdata from the European Community Household Panel Survey. Another study by Foley and O'Callaghan (2009), using micro data from the 2007 National Employment Survey, also find a sizable public sector wage premium, highest at the lower ends of the earnings distribution. Campos and Pereira (2009) for Portugal show that public sector employees earn higher wages than their private sector counterparts and this premium has risen over the 19962005 period from almost 10 per cent in 1996 to around 15 per cent in 2005 . The premium is higher for female workers compared to male workers and decreases as one moves from the lower to the upper quantiles of the earnings distribution. Ramos et al. (2014) use data from the Spanish Wage Structure Survey in 2010 and also report that public sector employees earn higher wages than their private sector counterparts. However, once characteristics of both the worker and the firm are taken into account the premium is relatively small, specially for men workers under fixed-term contracts. ${ }^{5}$ Giordano et al. (2011) use data from the European Union Statistics on Income and Living Conditions (EU-SILC) referring to the period 2004-2007. They evaluate the differential across countries, distinguishing by gender, educational level, sub-sectors and firm size. ${ }^{6}$

Finally, there exists a recent literature that estimate public - private wage gaps controlling for employees' observed and unobservable individual attributes using fixed effects quantile regressions. Bargain and Melly (2008) estimate the public wage gap in France for the period 1990-2002 at the mean and at different quantiles of the wage distribution for both men and women controlling for unobserved heterogeneity. They find that public sector premia or penalties are indeed much lower than commonly found. In particular, public wage premia for women and penalties for men are the result of the selection of the employees. Finally, only small pay differences between sectors remain over time, reflecting fluctuations due to specific public policies and the procyclical movement of private sector wages. Campos and Centeno (2012) use data for 15 European countries from the ECHP for the period 1994-2001. They find that estimates for the public-private wage gap based on the fixed effects approach are generally lower than those obtained using the pooled approach (with the only exception of Finland). Indeed, in most countries, once both observed and time-invariant unobservable factors are controlled

\footnotetext{
${ }^{5}$ Similar results are obtained by Rahona et al. (2013), also using data from the Wage Structure Survey but applying different sample selection filters.

${ }^{6}$ Other studies along these lines include Poterba and Rueben (1995), Nielsen and Rosholm (2001), and Jürges (2002).
} 
for, there is no evidence of a positive wage gap between the public and the private sectors. Individual heterogeneity contributes to attenuate the public-private wage gap along the entire distribution as well. According to Campos and Centeno (2012) this means that the observed compression in the public sector wage distribution would be due to selection. In most countries, sample differences between fixed effects and traditional QR estimates are more obvious at the lower quantiles of the wage distribution, suggesting that the positive selection effect becomes less obvious as one moves up the wage distribution.

\section{Data}

Our main data source is the Continuous Sample of Working Histories (Muestra Continua de Vidas Laborales, MCVL, in Spanish). The MCVL is a micro-level dataset built upon Spanish administrative records with detailed information on labor earnings and days worked, in addition to other worker and firm characteristics. It is a representative sample of the population registered with the social security administration at any time in the reference year. The MCVL also has a longitudinal design. From 2005 to 2012, those individuals who are present in a wave and subsequently remain registered with the social security administration stay as sample members. In addition, the sample is refreshed with new sample members so it remains representative of the population in each wave. Finally, the MCVL tries to reconstruct the market labor histories of the individuals in the sample back to 1967. Besides the MCVL, we will use annual income information from tax files that have been matched to the social security sample. Contrary to the social security measure of labor earnings that is top- (and bottom-) coded, tax records are not subject to censoring. In addition, as mentioned before, the MCVL does not record hours of work. Hence, in order to compute a hourly wage measure, we combine the daily earnings from administrative records with information on hours of work from the Spanish Labor Force Survey (Encuesta de Población Activa, EPA, in Spanish).

\subsection{Sample Selection}

The population of reference of the MCVL consists of all individuals registered with the social security administration, including pension earners, recipients of unemployment benefits, employees and self-employed workers, but excluding those registered only as medical care recipients, or those with a different social assistance system. The raw data represents a 4 per cent non-stratified random sample of this reference population. It consists of nearly 1.1 million individuals each year.

We use data from working individuals in the 2005-2012 MCVL original samples with Tax Information. $^{7}$ We select prime-age employees enrolled in the General Regime of the Social

\footnotetext{
${ }^{7}$ Basque Country and Navarra are excluded, because they enjoy a different system known as the Economic accord.
} 
Security Administration at any time in the sample period. ${ }^{8}$ To ensure that we only consider income from wage sources, we exclude self-employees from our sample. We also exclude individuals younger than 25 and older than 54 years to avoid to get mixed with formal education enrollments issues and early retirement decisions, respectively.

In the empirical analysis, we use individual log hourly wages as our main dependent variable. To recover the information on hours of work from the EPA, we define cells given by year, age, gender, level of qualification, sector of activity, tenure in the firm, type of contract (fixed-term vs. open-ended), type of work schedule (full-time vs. part-time), and region. For each cell in the EPA, we compute the average number of usual weekly hours of work, and then we impute that number to those individuals belonging to an equally defined cell in the MCVL dataset. Then we divide those hours by 5 to obtain daily hours of work. With this procedure, we have been able to merge 88 per cent of the observations from our MCVL raw sample. Hourly wages are computed as the individual annual labor income from the tax record, divided by the individual annual days of work from the social security records and the average number of daily hours obtained from the EPA.

The merged final sample is a panel of 688,607 individuals and 3,232,618 annual observations for the period 2005-2012. We present descriptive statistics on sample composition in Table A.1.

\subsection{Definition of Public Employees}

In our dataset public employees refer to those workers from either the central administration, the regional governments or the local corporations, as well as those working in public firms. ${ }^{9}$ However, some public employees who belong to social assistance systems different to the General Regime of the Social Security Administration, such as the armed forces, the judicial power or MUFACE, are not generally included.

According to our dataset, in Spain 15 per cent of employees work in the public sector (see Table 1). In the case of women the incidence is higher (20 per cent), almost doubles the corresponding share for men (11 per cent). By skill groups, ${ }^{10}$ we obtain that the share of public employees is higher among high-skilled relatively to less skilled workers. One particular feature of the Spanish case is the high proportion of public employees among workers with fixed-term contracts (more than 31 per cent for women).

\footnotetext{
${ }^{8}$ In Spain, more than 95 per cent of employees are enrolled in the general scheme of the Social Security Administration. Separate schemes exist for domestic workers, some workers in fishing, mining and agricultural activities, and some government employees, such as the armed forces, the judicial power or MUFACE (Mutualidad General de Funcionarios Civiles del Estado).

${ }^{9}$ The dataset includes two variables that allow us to distinguish workers in the public sector to those in the private sector: one from the point of view of the worker (so-called employee type), and another from the firm's perspective (type of legal entity). The results presented in the paper correspond to the first definition. We also use the second definition as a robustness check, and the results do not change.

${ }^{10}$ In Spain, each worker affiliated to the social security is assigned to one of the ten contribution groups (for instance, Group 1 corresponds to workers with university degree). In particular, we label a worker as high-skilled (groups 1-3), medium-skilled (groups 4-7), or low-skilled (groups 8-10).
} 
Table 1: Share of public employees (\%)

\begin{tabular}{lccc}
\hline \hline & All & Men & Women \\
\hline Overall & 15.16 & 10.82 & 20.36 \\
High-skilled & 34.82 & 23.06 & 46.93 \\
Medium-skilled & 16.98 & 16.57 & 17.24 \\
Low-skilled & 7.16 & 5.29 & 10.95 \\
Permanent & 12.12 & 10.26 & 14.43 \\
Temporary & 21.17 & 11.99 & 31.51 \\
\hline Notes: Whole sample (2005-2012). High-skilled \\
(1-3), medium-skilled (4-7), low-skilled (8-10). \\
\hline \hline
\end{tabular}

The evolution of those shares over time, as shown in Figure 1, is clearly affected by the current crisis. We can see than before 2009 the public sector share was 14.6 per cent, then increases up to 16.2 from 2009 to 2011, before decreasing to 14.0 per cent in 2012. For men, the increase in the share was from 10.1 to 11.9 , and then it decreases to 10.5 per cent, while in the case of women, the corresponding numbers are 20.3, 21.2, and 18.0, respectively.

Figure 1: Share of public employees over time $(\%)$

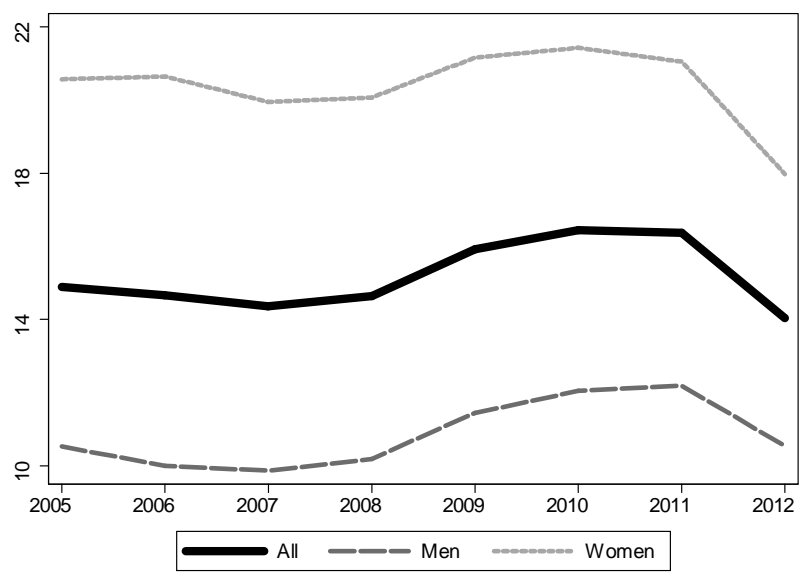

Notes: Whole sample (2005-2012).

\subsection{A First Glimpse of the Data: Raw Wage Gaps}

According to Table 2, annual earnings are on average 34 per cent higher in the public sector than in the private sector over the period. However, part of this raw gap is due to the different labor force composition of the two sectors. As reported in the Table A.2 of the Appendix, public employees are on average older, more skilled, have longer tenure and work more on a full-time 
basis. On the other hand, they have temporary contracts in a higher proportion.

Table 2: Average Raw Wage Gap (\%)

\begin{tabular}{lccc}
\hline \hline & All & Men & Women \\
\hline Annual earnings & 33.6 & 30.2 & 55.5 \\
Daily earnings & 27.2 & 21.1 & 49.4 \\
Hourly wages & 31.7 & 30.8 & 39.7 \\
\hline \multicolumn{4}{l}{ Notes: Whole sample (2005-2012). } \\
\hline \hline
\end{tabular}

In addition, the gap in annual earnings includes differences in the total number of days worked in a year, and in the number of hours worked per day. On the one hand, the number of annual days of work is on average higher in the public sector. Given that, the raw public sector wage gap is lower in a daily basis than in annual terms (27\% versus $34 \%)$. On the other, employees in the public sector work on average less hours than those in the private sector (7.3 and 7.6 hours per day, respectively), being then the public sector hourly wage gap on average equal to $31.7 \%$. By gender, we obtain than the raw wage premium in the public sector is higher for females than for males (39.7\% and $30.8 \%$, respectively). Also, in the case of women, the average public wage gap is lower in a hourly basis than in a daily basis because daily hours of work are higher in the public sector due to the prevalence of part-time contracts in the private sector (see Table A.2).

Figure 2 shows the evolution of the public sector wage gap over time. We can see that the average wage gap increased from 2005 to 2009 and then decreased (with the overall gap being the highest in 2009, 38.8 per cent, and the lowest in 2012, 21.5 per cent). This decrease in the public sector wage gap goes in line with the recent cuts in public wages.

Behind those differences by gender in the average public sector wage gap there are very different profiles along the wage distribution. As shown in Figure 3, for men we observe an inverse $\mathrm{V}$-shaped pattern, whereas for women the profile is more compressed and similar to an inverse U. Over time, those profiles have changed in terms of the level and only recently also in their shapes; in particular, the change in the shapes in 2012 might be explained by the wage moderation process in the aftermath of the crisis, which seems to be especially important for private sector workers at the bottom of the wage distribution.

Next, we consider the public sector wage gap in the presence of covariates - first in the mean and next over the entire wage distribution - in order to isolate the part of the gap due to differences in the remunerations to those observed characteristics. Finally, we perform the same decomposition exercise while also accounting for time-invariant unobserved characteristics, i.e., endogenous selection into the public sector. 
Figure 2: Hourly wages and average gap (\%) over time
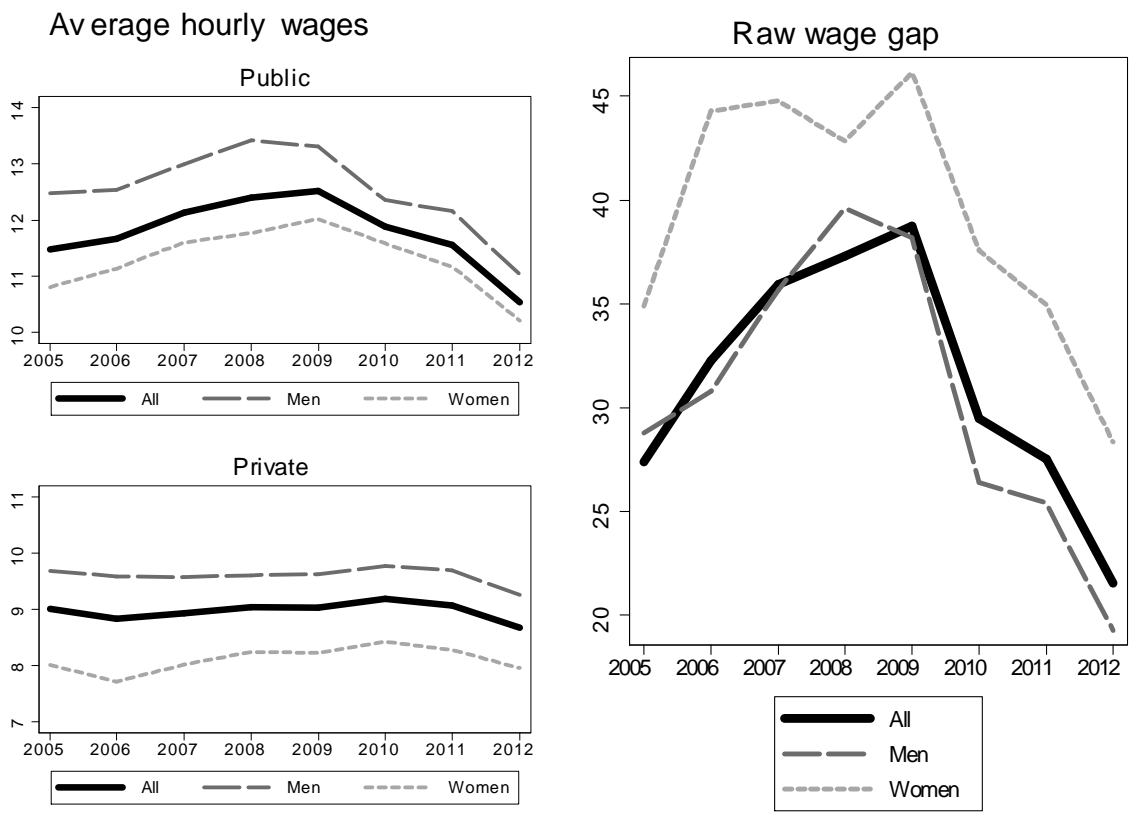

Figure 3: Raw gaps (\%) along the wage distribution over time
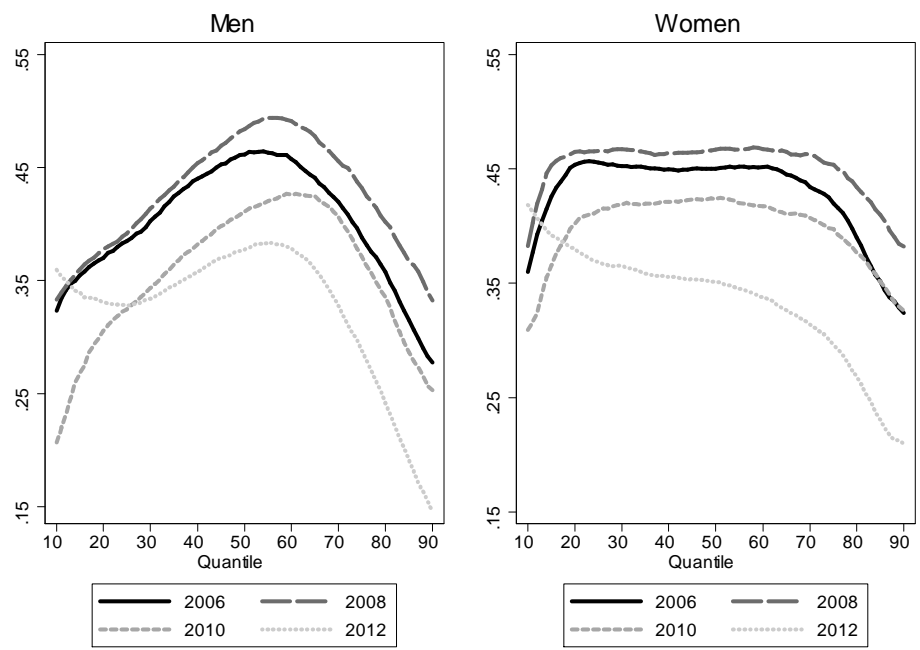


\section{Preliminary Evidence: The Average Public Sector Wage Gap}

\subsection{Oaxaca-Blinder decomposition}

Blinder (1973) and Oaxaca (1973) proposed to decompose the difference in average earnings between public and private workers into a explained component given by differences in characteristics and an unexplained component given by differences in coefficients. Formally, let $y_{i}$ be the individual $i$ 's log hourly wage in real terms (in a given year, or in the pooled data for the whole period). We denote Public $\equiv 1$ and Private $\equiv 0$, so that we consider the following regressions for each sector:

$$
\begin{aligned}
& y_{i 1}=x_{i 1} \beta_{1}+u_{i 1} \\
& y_{i 0}=x_{i 0} \beta_{0}+u_{i 0}
\end{aligned}
$$

where $x_{i}$ is the set of covariates in each case. Let $\bar{z}=N^{-1} \sum_{i} z_{i}$ be a sample mean, and $\bar{x}_{1} \beta_{0}$ a counterfactual wage that measures the average wage we would observe if public workers would be paid as private workers. Then, the average difference in wages between the two sectors is:

$$
\begin{aligned}
& \bar{y}_{1}-\bar{y}_{0}=\bar{x}_{1} \beta_{1}-\bar{x}_{0} \beta_{0}+\bar{x}_{1} \beta_{0}-\bar{x}_{1} \beta_{0} \\
& \bar{y}_{1}-\bar{y}_{0}=\underbrace{\left(\bar{x}_{1}-\bar{x}_{0}\right) \beta_{0}}_{\text {Characteristics effect (Explained) }}+\underbrace{\bar{x}_{1}\left(\beta_{1}-\beta_{0}\right)}_{\text {Coefficients effect (Unexplained) }}
\end{aligned}
$$

This simple derivation allow us to decompose the average difference between wages in the public and private sectors in two components: the characteristics effect (an explained component given by differences in composition), and the coefficients effect (an unexplained component given by differences in returns).

\subsection{Results}

In Table 3 we present estimates of the coefficients effect, that is, the difference in average log hourly wages between public and private workers once the effects of differences in characteristics is net out. We show estimates for the whole period, in column 1 pooling men and women, and in columns 2 and 3 for each of them separately. With respect to the vector of covariates $\left(x_{i}\right)$, we consider three different specifications: first, we consider those variables often included in Mincerian models, namely, age, age squared, skill-groups, time and regional dummies; second, we add indicators for tenure in the firm (less than 1 year, between 1 and 2 years, between 2 and 4, between 4 and 7, between 7 and 15, and more than 15 years), the type of contract (permanent or fixed-term vs. temporary or open-ended), and the type of work schedule (full-time vs. parttime); and finally, we also include firm size as an additional categorical variable (less than 10 employees, 10-50, 50-200, more than 200). ${ }^{11}$

\footnotetext{
${ }^{11}$ These models correspond to specification 1, 2 and 3, respectively, in subsequent tables and figures. For regressions that pool men and women together we add a female indicator. Coefficient estimates of these regressions are available upon request.
} 
We find that for an overall raw difference of $0.35 \mathrm{log}$ points, between 0.12 and $0.15 \mathrm{log}$ points (depending of the specification) are explained by differences in observed characteristics of public and private workers. However, there is still almost one half of the difference that remains unexplained. For men, the raw log difference is 0.35 and at least 53 per cent of the difference is due to the coefficients effect. For women, the raw difference is higher (0.40) but again the fraction unexplained is around one half of it.

Table 3: Average logwage difference

\begin{tabular}{lccc}
\hline \hline & All & Men & Women \\
\hline Raw difference & 0.355 & 0.349 & 0.401 \\
& $(0.001)$ & $(0.001)$ & $(0.001)$ \\
Coefficients Effect (Specification 1) & 0.203 & 0.195 & 0.207 \\
& $(0.001)$ & $(0.002)$ & $(0.001)$ \\
Coefficients Effect (Specification 2) & 0.239 & 0.213 & 0.267 \\
& $(0.001)$ & $(0.002)$ & $(0.002)$ \\
Coefficients Effect (Specification 3) & 0.205 & 0.185 & 0.231 \\
& $(0.001)$ & $(0.002)$ & $(0.002)$ \\
\hline Notes: Whole sample (2005-2012). SE in parentheses. & & \\
\hline \hline
\end{tabular}

In Figure 4 we show the raw differences and the estimates of the coefficients effect from Specification 3 - overall and by gender - for each year. We find that the raw log difference increases from 0.35 in 2005 to 0.39 in 2008, and then diminishes to 0.31 in 2012. In addition, we estimate that in 2005, 37 per cent of the raw log difference was due to the coefficients effect, 42 per cent in 2008, and only 7 per cent of the gap in 2012 remained unexplained. For males, the evolution of the raw gap is from 0.35 in 2005, to 0.39 in 2008 and 0.31 in 2012, whereas for women the corresponding figures are $0.41,0.43$ and 0.34 , respectively. With respect to the size of the coefficients effect, for men it moves from 20 per cent in 2005 to 27 per cent in 2008, whereas in 2012 is essentially non-existent. For women, the effect moves from 44 per cent in 2005 to 50 per cent in 2008, and to 16 per cent in 2012. The reduction in the share of the gap explained by the coefficients may well be explained by recent across-the-board measures to reduce public wages given a relatively similar composition of the workforce in terms of observable characteristics.

\subsection{Contributions to the Public Wage Gap}

In this section, we analyze the detailed contributions of the single covariates or sets of covariates to the public wage gap. For example, we are interested in exploring how much of the public wage gap is due to differences in tenure and how much is due to differences in skills between public and private sector workers. Similarly, we also determine how much of the unexplained gap is related to differing returns to skills and how much to differing returns to work experience. 
Figure 4: Average logwage difference over time

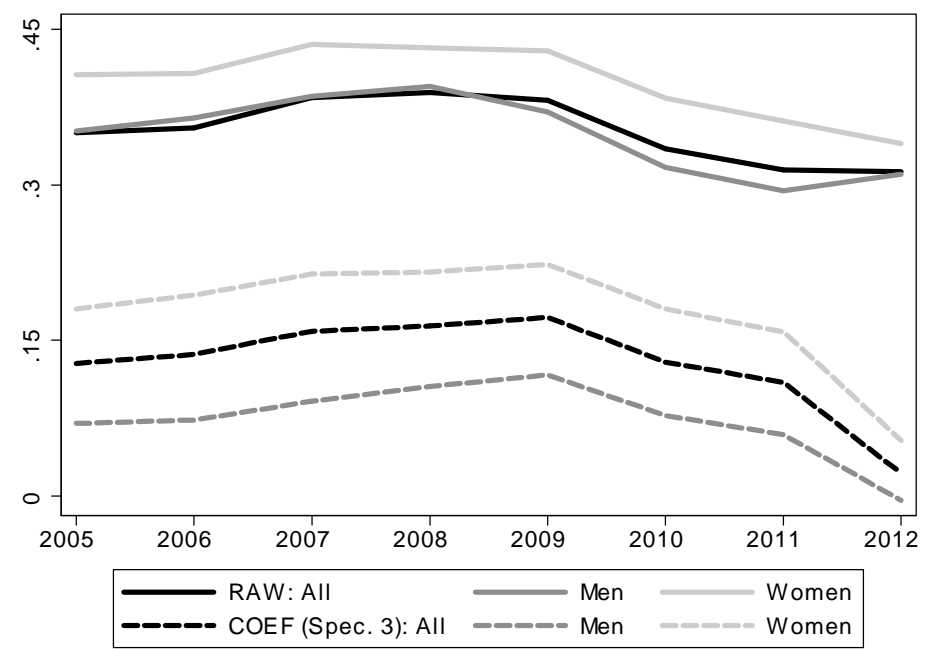

Crucially, our econometric specification is mostly based on categorical variables such as the skill-group or tenure dummies. In the case of categorical variables, the identification problem in the decomposition equation is a disguised identification problem of constant and dummy variables in a regression equation. As a result, the decomposition results depend on the choice of the omitted base category. To overcome this challenge, we consider the normalization method proposed in Gardeazabal and Ugidos (2004), which is invariant to the "left-out" reference category in computing the contribution of categorical variables to the coefficients effect; futher, it alters neither the detailed characteristics effect, nor the contribution of continuous variables to the coefficients effect.

Table 4 reports the detailed decomposition of the public wage gap. Regarding the characteristics effect, observed differences in skills explain most of the wage differential, whereas the remaining observable characteristics do not seem to matter much. In particular, the part of the characteristics effect explained by skills is $0.143 \log$ points, which represents $95 \%$ of the total characteristics effect in the case of the overall sample; this share is $73 \%$ and $97 \%$ for men and women respectively. ${ }^{12}$ Turning to the coefficients effect, the constant term explains most of the unexplained gap in the overall sample, which indeed points to the importance of differences in remunerations to unobservable characteristics (see Section 6).

\footnotetext{
${ }^{12}$ This difference between men and women is mostly explained by the lower incidence of part-time and temporary contracts among men in the private sector.
} 
Table 4: Detailed Oaxaca-Blinder decomposition

\begin{tabular}{|c|c|c|c|c|c|c|}
\hline \multirow[b]{2}{*}{ Raw difference } & \multicolumn{2}{|c|}{ All } & \multicolumn{2}{|c|}{ Men } & \multicolumn{2}{|c|}{ Women } \\
\hline & 0.355 & $(0.001)$ & 0.350 & $(0.001)$ & 0.401 & $(0.001)$ \\
\hline \multicolumn{7}{|c|}{ Characteristics effect } \\
\hline Age & 0.014 & $(0.000)$ & 0.013 & $(0.000)$ & 0.016 & $(0.000)$ \\
\hline Education & 0.143 & $(0.001)$ & 0.120 & $(0.001)$ & 0.165 & $(0.001)$ \\
\hline Region & -0.006 & $(0.000)$ & -0.002 & $(0.000)$ & -0.009 & $(0.000)$ \\
\hline Time & 0.002 & $(0.000)$ & 0.000 & $(0.000)$ & 0.003 & $(0.000)$ \\
\hline Contract & -0.032 & $(0.000)$ & -0.008 & $(0.000)$ & -0.054 & $(0.001)$ \\
\hline Tenure & 0.008 & $(0.000)$ & 0.012 & $(0.000)$ & 0.007 & $(0.000)$ \\
\hline Firm size & 0.039 & $(0.001)$ & 0.029 & $(0.001)$ & 0.042 & $(0.001)$ \\
\hline Female & -0.018 & $(0.000)$ & & & & \\
\hline Total & 0.150 & $(0.001)$ & 0.165 & $(0.002)$ & 0.170 & $(0.002)$ \\
\hline \multicolumn{7}{|c|}{ Coefficients effect } \\
\hline Age & 0.006 & $(0.017)$ & 0.124 & $(0.027)$ & -0.117 & $(0.022)$ \\
\hline Education & 0.031 & $(0.001)$ & 0.031 & $(0.001)$ & 0.024 & $(0.001)$ \\
\hline Region & 0.001 & $(0.001)$ & 0.013 & $(0.002)$ & -0.012 & $(0.001)$ \\
\hline Time & 0.001 & $(0.000)$ & 0.001 & $(0.000)$ & 0.000 & $(0.000)$ \\
\hline Contract & -0.047 & $(0.001)$ & -0.075 & $(0.001)$ & -0.022 & $(0.001)$ \\
\hline Tenure & 0.018 & $(0.001)$ & 0.016 & $(0.001)$ & 0.022 & $(0.001)$ \\
\hline Firm size & 0.022 & $(0.000)$ & 0.031 & $(0.001)$ & 0.017 & $(0.001)$ \\
\hline Female & 0.037 & $(0.001)$ & & & & \\
\hline Constant & 0.135 & $(0.017)$ & 0.044 & $(0.027)$ & 0.318 & $(0.022)$ \\
\hline Total & 0.205 & $(0.001)$ & 0.185 & $(0.002)$ & 0.231 & $(0.002)$ \\
\hline Notes: Whole sam & $\begin{array}{l}5-2012) . \\
\text { ontract, te }\end{array}$ & $\begin{array}{l}\text { ge refers } t \\
\text { nure, and } \mathrm{f}\end{array}$ & $\begin{array}{l}\text { the effec } \\
\text { rm size re }\end{array}$ & $\begin{array}{l}\text { of the var } \\
\text { fer to the } \mathrm{s}\end{array}$ & $\begin{array}{l}\text { ables age } \\
\text { kill-group }\end{array}$ & $\begin{array}{l}\text { age squar } \\
\text { ion, year, }\end{array}$ \\
\hline
\end{tabular}




\section{The Public Sector Wage Gap over the Distribution}

\subsection{Counterfactual Distributions}

The popular Oaxaca-Blinder decomposition only provides information about average differences. However, statistical measures of the public-private wage gap based on average effects might mask important differences along the distribution of wages.

Since Koenker and Bassett (1978) the quantile regression approach has became relatively popular to study the effects of a covariate $(X)$ on the whole conditional distribution of the dependent variable $(Y)$. Quantile regression provides a more complete picture of the conditional distribution of $Y$ given $X=x$ when both lower and upper quantiles are of interest. More concretely, we can specify the $\theta$ th quantile of the conditional distribution of $y_{i}$ given $X_{i}$ as a linear function of the covariates,

$$
Q_{\theta}\left(y_{i} \mid X_{i}\right)=X_{i} \beta_{\theta}, \quad \theta \in(0,1)
$$

The quantile regression estimator of $\beta_{\theta}$ estimates the effect of the covariates on the $\theta$ th quantile of the dependent variable and solves the following problem (Koenker and Bassett, 1978): ${ }^{13}$

$$
\hat{\beta}_{\theta}=\operatorname{argmin}_{\beta}\left[\sum_{i \in\left\{i: y_{i} \geq X_{i} \beta\right\}} \theta\left|y_{i}-X_{i} \beta\right|+\sum_{i \in\left\{i: y_{i}<X_{i} \beta\right\}}(1-\theta)\left|y_{i}-X_{i} \beta\right|\right] .
$$

Given the quantile regression approach just discussed, we can now present the details on the generalization of the Blinder-Oaxaca decomposition to the whole distribution of wages based on CFVM. In particular, we can proceed in seven steps:

Step 1. Quantile regressions: We separately run two different sets of quantile regressions, one for the public sector (group 1) and one for the private sector (group 0) to obtain the two sequences of quantile coefficients $\hat{\beta}_{\theta_{j}}^{1}$ and $\hat{\beta}_{\theta_{j}}^{0}$ for $j=1, \ldots, J$ with $\theta_{j} \in(0,1) \forall j$. Despite asymptotically one could estimate an infinite number of quantile regressions for each group (i.e. $J \rightarrow \infty$ ), following the suggestion in Portnoy (1991) we only estimate 150 different regressions to approximate the whole quantile function (i.e. $J=150) .{ }^{14}$

Step 2. Conditional quantile functions: Given the quantile regression coefficients obtained in the first step, it is straightforward to estimate the $\theta_{j}$ 's conditional quantile of $Y_{g}$ given $X_{i}$ by computing $X_{i}^{\prime} \hat{\beta}_{\theta_{j}}^{g}$ where $g=(0,1)$ represents the group (public or private workers). Hence we can construct the two conditional quantile functions as follows:

$$
\begin{aligned}
& \hat{q}_{\theta_{j}}^{1}=X_{i}^{\prime} \hat{\beta}_{\theta_{j}}^{1} \quad \forall j=1, \ldots, J \\
& \hat{q}_{\theta_{j}}^{0}=X_{i}^{\prime} \hat{\beta}_{\theta_{j}}^{0} \quad \forall j=1, \ldots, J .
\end{aligned}
$$

\footnotetext{
${ }^{13}$ Buchinsky (1998) provides an overview of the quantile regression estimator together with details on its asymptotic covariance matrix.

${ }^{14}$ In finite samples, Portnoy (1991) shows that given the set of points in which the vector of coefficients changes $\left(\theta_{0}=0, \theta_{1}, \ldots, \theta_{J}=1\right)$, the coefficients estimate $\hat{\beta}_{\theta_{j}}$ prevails in the interval from $\theta_{j-1}$ to $\theta_{j}$.
} 
Step 3. Conditional distribution functions: We can also estimate the conditional distribution function by inverting the conditional quantile function obtained in step 2 so that: ${ }^{15}$

$$
\begin{aligned}
& \hat{F}_{Y_{1}}\left(q \mid X_{i}\right)=\int_{0}^{1}\left(1\left(X_{i}^{\prime} \hat{\beta}_{\theta_{j}}^{1} \leq q\right) d \theta\right)=\sum_{j=1}^{J}\left(\theta_{j}-\theta_{j-1}\right) 1\left(X_{i}^{\prime} \hat{\beta}_{\theta_{j}}^{1} \leq q\right) \\
& \hat{F}_{Y_{0}}\left(q \mid X_{i}\right)=\int_{0}^{1}\left(1\left(X_{i}^{\prime} \hat{\beta}_{\theta_{j}}^{0} \leq q\right) d \theta\right)=\sum_{j=1}^{J}\left(\theta_{j}-\theta_{j-1}\right) 1\left(X_{i}^{\prime} \hat{\beta}_{\theta_{j}}^{0} \leq q\right) .
\end{aligned}
$$

where $F_{Y}(q)$ refers to the cumulative distribution function (CDF) of the random variable $Y$ evaluated at $q, F_{Y}^{-1}(\theta)$ represents the inverse of the CDF, also known as quantile function evaluated at $0<\theta<1$, and $F_{Y}\left(q \mid X_{i}\right)$ refers to the conditional $\mathrm{CDF}$ of $Y$ evaluated at $q$ and given the realization $X=X_{i}$.

Step 4. Unconditional distribution functions: Therefore, we can now estimate the unconditional distribution function for public $(g=1)$ and private $(g=0)$ workers as follows:

$$
\begin{aligned}
& \hat{F}_{Y_{g}}(q \mid g=1)=\int \hat{F}_{Y_{g}}(q \mid x) d F_{X}(x \mid g=1)=\frac{1}{n_{1}} \sum_{i: g=1} \hat{F}_{Y_{g}}\left(q \mid X_{i}\right) . \\
& \hat{F}_{Y_{g}}(q \mid g=0)=\int \hat{F}_{Y_{g}}(q \mid x) d F_{X}(x \mid g=0)=\frac{1}{n_{0}} \sum_{i: g=0} \hat{F}_{Y_{g}}\left(q \mid X_{i}\right) .
\end{aligned}
$$

where $n_{1}$ and $n_{0}$ are the number of public and private workers in the sample.

Step 5. Unconditional quantile functions: Given our interest in simulating counterfactual quantiles to decompose differences in the distribution of wages, we estimate the unconditional quantile function. For this purpose we take as an estimator of the $\theta^{\text {th }}$ quantile of the unconditional distribution from step 4 the minimum of the set as follows:

$$
\begin{aligned}
& \hat{q}_{\theta}^{1}=\inf \left\{q: \frac{1}{n_{1}} \sum_{i: g=1} \hat{F}_{Y_{1}}\left(q \mid X_{i}\right) \geq \theta\right\} \\
& \hat{q}_{\theta}^{0}=\inf \left\{q: \frac{1}{n_{0}} \sum_{i: g=0} \hat{F}_{Y_{0}}\left(q \mid X_{i}\right) \geq \theta\right\} .
\end{aligned}
$$

Step 6. Counterfactual quantile functions: Armed with the previous function estimates, we are now able to estimate the counterfactual quantile function. That is, we estimate the $\theta^{\text {th }}$ quantile of the distribution that we would observe if public workers $(g=1)$ would be paid as private workers $(g=0)$ :

$$
\hat{q}_{\theta}^{c}=\inf \left\{q: \frac{1}{n_{1}} \sum_{i: g=1} \hat{F}_{Y_{0}}\left(q \mid X_{i}\right) \geq \theta\right\} .
$$

where $n_{1}$ is the number of public workers in the sample. Note that for the construction of the conditional distribution $\hat{F}_{Y_{0}}\left(q \mid X_{i}\right)$ we used in step 3 the coefficients estimated for the private

\footnotetext{
${ }^{15}$ Note that since the estimated quantile function might not be monotonic, we need to resort to the following property of the CDF: $F_{Y_{g}}\left(q \mid X_{i}\right)=\int_{0}^{1}\left(1\left(F_{Y_{g}}^{-1}\left(\theta \mid X_{i}\right) \leq q\right) d \theta\right)=\int_{0}^{1}\left(1\left(X_{i}^{\prime} \beta_{\theta_{j}}^{g} \leq q\right) d \theta\right)$.
} 
workers, i.e., $\hat{\beta}_{\theta}^{0}$; and we are computing the counterfactual quantile using the $X \mathrm{~s}$ among public workers, i.e., sum over individuals with $g=1$. This counterfactual distribution is an interesting object per se that will deserve special attention in our empirical exercises.

Step 7. Decomposition: Analogously to the Blinder-Oaxaca approach for the mean, we can now compute a decomposition of the difference between the $\theta^{\text {th }}$ quantile of the unconditional distribution of public and private workers:

$$
\hat{q}_{\theta}^{1}-\hat{q}_{\theta}^{0}=\underbrace{\left[\hat{q}_{\theta}^{c}-\hat{q}_{\theta}^{0}\right]}_{\text {Characteristics Effect }}+\underbrace{\left[\hat{q}_{\theta}^{1}-\hat{q}_{\theta}^{c}\right]}_{\text {Coefficients Effect }}
$$

\subsection{Results}

Similarly to the comparison before at the mean, now we compare the estimated percentiles of the total public sector logwage gap, $\hat{q}_{\theta}^{1}-\hat{q}_{\theta}^{0}$, with the corresponding ones once the contribution of different characteristics has been net out (that is, the coefficients effect $\hat{q}_{\theta}^{1}-\hat{q}_{\theta}^{c}$ ). ${ }^{16}$ Figure 5 shows those percentiles by gender for the three specifications considered. The solid lines stand for the estimated total wage gaps, while the dashed lines correspond to the estimated wage gaps once the contribution of the sample composition has been net out. Table 5 summarizes point estimates at selected quantiles. ${ }^{17}$

In the case of the conditional mean, as reported in Table 3, we obtained that around half of the public sector raw wage gap was explained by differences in observable characteristics. Similarly, we find that if workers in the private and in the public sectors had the same characteristics, the public sector wage gap along the wage distribution would be significantly lower, especially at the top. In fact, for men in the upper-part of the distribution, the positive wage gap practically disappears (the gap ranges 0.054-0.064 depending on the specification). This means that a substantial fraction of the public sector gap is due to the fact that public employees are in general better in terms of covariates than private sector employees. The table also shows that the three specifications perform similarly in terms of the fit (which is remarkably good), and that the three offer similar estimates of the unconditional quantiles. Results from here onwards are all obtained using specification $3 .^{18}$

With respect to the evolution of the public sector wage gap over time, to easy the presentation and analyses of results, we focus on two particular years: 2008 and 2012. Figure 6 shows the percentiles of the two public sector wage gaps (total - solid lines; and coefficients - dashed lines) by gender for those two years.

From 2008 to 2012 we see that the public sector raw wage gap has decreased substantially both for men and women, with the only exception of the 10th percentile. Once the contribution

\footnotetext{
${ }^{16}$ These estimates are based on quantile regressions presented in Appendix B.1.

${ }^{17}$ Given the huge sample size we consider there is not need to include standard errors in the tables or figures. To illustrate this point Figure A.1 in the Appendix show how tight are the confidence intervals in the case of a 5 per cent random draw of the sample the we use. Standard errors are computed by bootstrap and the computational burden is very high.

${ }^{18}$ Results from the two other specifications are available upon request.
} 
Figure 5: Estimated gaps along the wage distribution
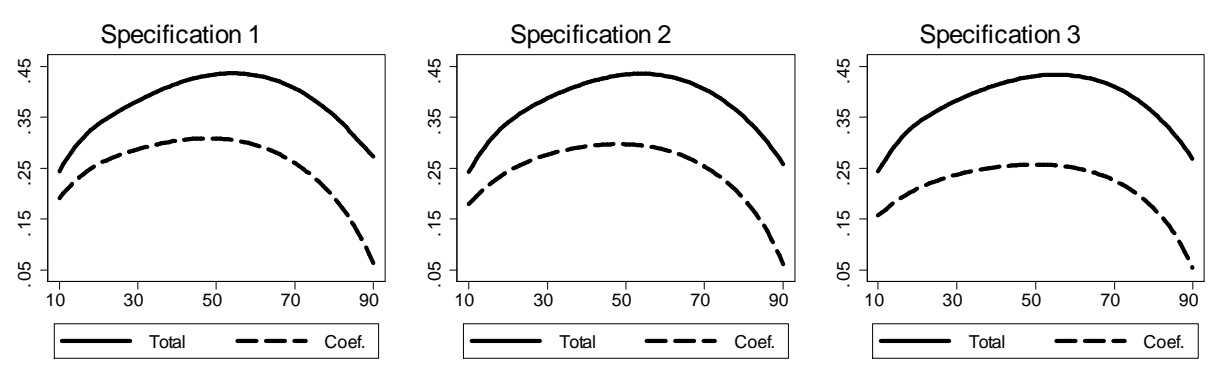

\section{Women}
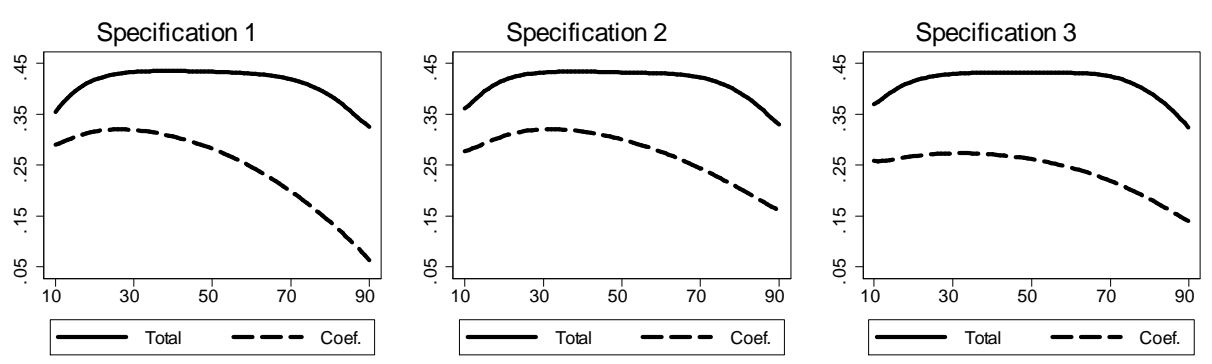

Notes: Whole sample (2005-2012).

Table 5: Estimated gaps along the wage distribution

\begin{tabular}{|c|c|c|c|c|c|c|c|c|}
\hline & \multirow[b]{2}{*}{ Quantile } & \multirow[b]{2}{*}{ Sample } & \multicolumn{2}{|c|}{ Spec. 1} & \multicolumn{2}{|c|}{ Spec. 2} & \multicolumn{2}{|c|}{ Spec. 3} \\
\hline & & & Total & Coef. & Total & Coef. & Total & Coef. \\
\hline \multirow[t]{5}{*}{ Men } & 10 & 0.286 & 0.244 & 0.191 & 0.243 & 0.181 & 0.244 & 0.158 \\
\hline & 25 & 0.361 & 0.361 & 0.275 & 0.367 & 0.263 & 0.363 & 0.226 \\
\hline & 50 & 0.440 & 0.435 & 0.309 & 0.434 & 0.297 & 0.431 & 0.258 \\
\hline & 75 & 0.381 & 0.383 & 0.231 & 0.382 & 0.227 & 0.389 & 0.204 \\
\hline & 90 & 0.266 & 0.273 & 0.064 & 0.258 & 0.061 & 0.268 & 0.054 \\
\hline \multirow[t]{5}{*}{ Women } & 10 & 0.368 & 0.355 & 0.290 & 0.361 & 0.277 & 0.370 & 0.258 \\
\hline & 25 & 0.438 & 0.428 & 0.319 & 0.428 & 0.316 & 0.425 & 0.271 \\
\hline & 50 & 0.437 & 0.434 & 0.281 & 0.432 & 0.300 & 0.432 & 0.261 \\
\hline & 75 & 0.403 & 0.406 & 0.169 & 0.411 & 0.224 & 0.413 & 0.202 \\
\hline & 90 & 0.322 & 0.325 & 0.064 & 0.329 & 0.160 & 0.323 & 0.140 \\
\hline
\end{tabular}

Notes: Whole sample (2005-2012). Sample reports the difference between the $j$ quantile of $\log$ hourly wages in the public sector, $q_{j}^{1}$, and that in the private sector, $q_{j}^{0}$.

Total refers to $\hat{q}_{\theta_{j}}^{1}-\hat{q}_{\theta_{j}}^{0}$, and Coefficients to $\hat{q}_{\theta_{j}}^{1}-\hat{q}_{\theta_{j}}^{c}$. 

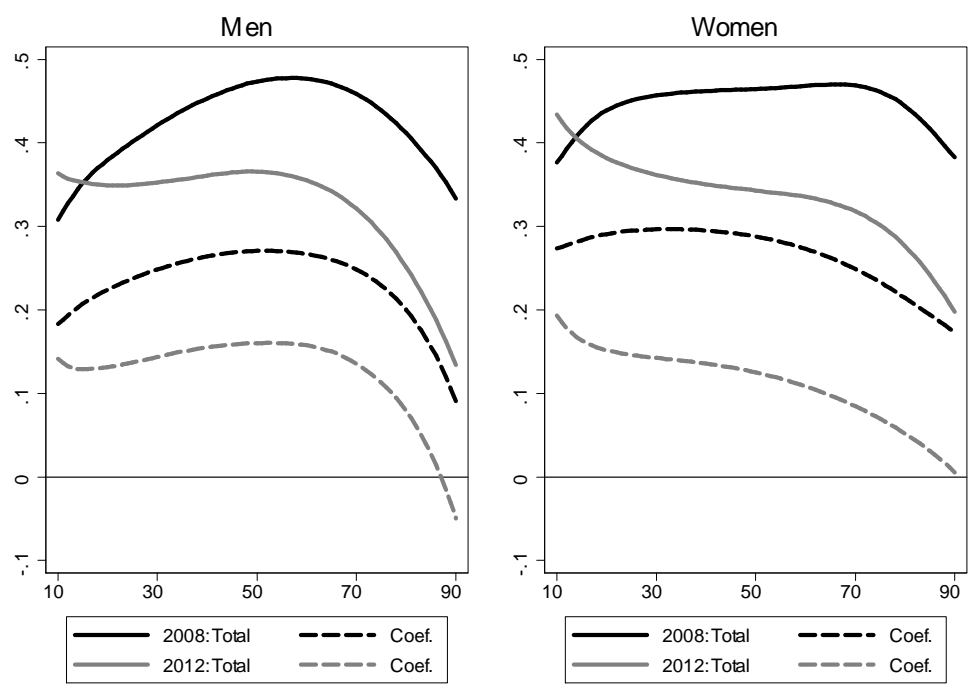

of observed characteristics is taken into account, we still observe significant decreases, with the conditional median wage gap for men moving from 0.27 in 2008 to 0.16 in 2012, and for women from 0.29 in 2008 to 0.12 in 2012 . At the 90th percentile, in 2012 the gap for men becomes negative and almost zero for women.

\subsection{Results by Subgroups of Workers}

We now consider two different subgroups of workers. We first consider workers by skill groups, distinguishing between high, medium and low skilled individuals. Second, we separate workers by type of contract, that is, those workers with a permanent contract versus those with a fixed-term or temporary position.

Figure 7 shows the percentiles of the public sector wage gaps by gender and skill level. As previously, the solid lines stand for the estimated total wage gaps, while the dashed lines correspond to the estimated wage gaps once the contribution of the sample composition has been net out.

For high-skilled and medium-skilled workers the total gap is decreasing along the distribution of wages, whereas for low-skilled workers the slope is positive in the bottom half of the distribution and flat or slightly negative in the upper part. Once we condition on observables, we find that if high-skilled male workers in the private and in the public sectors had the same characteristics, the public sector wage gap would be negative already at the median. For high-skilled women is always positive, but substantially lower. For medium and low-skilled male workers the role of characteristics is rather limited. Finally, for medium and low-skilled female workers the conditional public sector wage premium is higher than the total gap for observationally comparable individuals. 
Figure 7: Estimated gaps by skill level
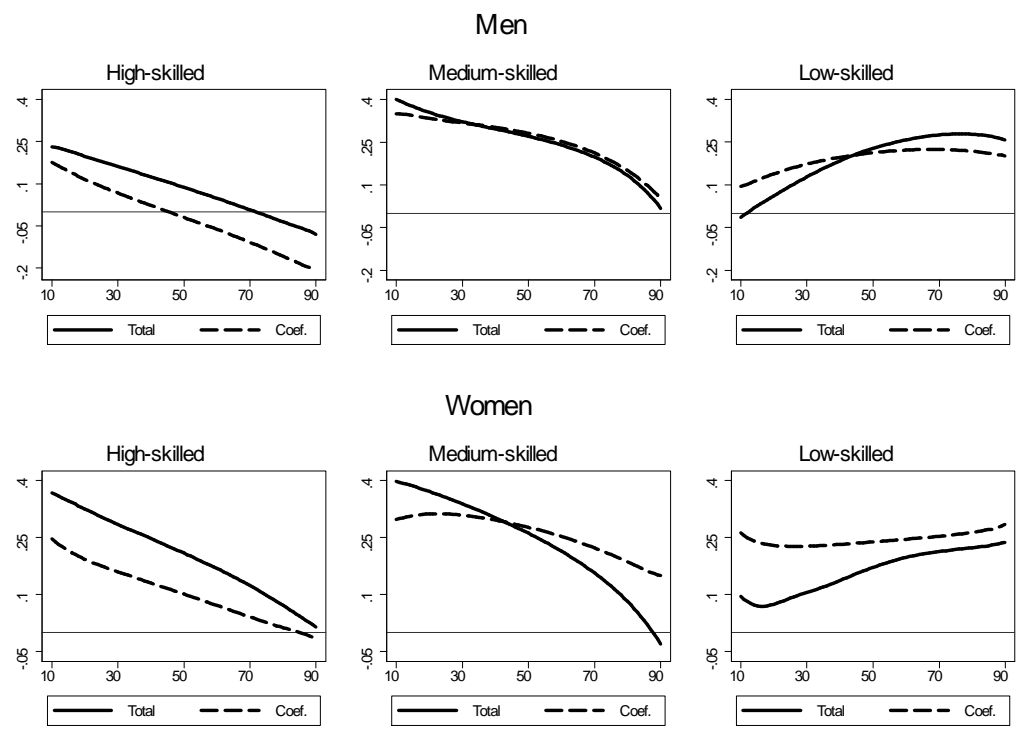

Notes: Whole sample (2005-2012).

In order to see the evolution over time, we report in Figure A.2 of the Appendix the percentiles of the public sector wage gaps in 2008 and 2012. From 2008 to 2012, we observe important decreases in all those gaps. The most salient facts are the following. For high-skilled male workers, the conditional public sector wage gap is negative already at the 21th percentile in 2012, and now also for women is negative from the 52th percentile onwards. For mediumskilled workers, the total gap in 2012 is negative at the very top of the distribution, but once composition is considered the gap is always positive. Finally, the uncommon increasing profile obtained for low-skilled workers in 2008 disappears in 2012.

Figure 8 shows the percentiles of the public sector wage gaps by gender and type of contract. Again, the solid lines stand for the estimated total wage gaps, while the dashed lines correspond to the estimated wage gaps once the contribution of the sample composition has been net out.

For workers with a permanent contract the public sector raw wage gap is in general decreasing, while - on the contrary - for temporary male workers the raw gap increases as wages also increase, and for temporary women it remains flat. Once composition is taken into consideration, the gap for indefinite positions falls in a parallel fashion, similarly to the case of women in temporary positions, whereas for men the gap adopts a concave shape.

Once again, to see the evolution over time, we depict in Figure A.3 of the Appendix the percentiles of the public sector wage gaps in 2008 and 2012. For permanent workers the falls in the gaps, both total and in coefficients, are parallel. For temporary workers, however, we find that the gaps from 2008 to 2012 rotate downward, adopting a decreasing shape more in line with previous evidence. 
Figure 8: Estimated gaps by type of contract

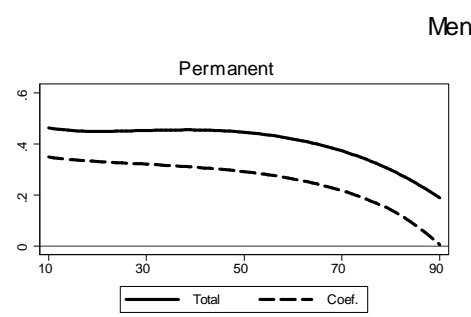

Men

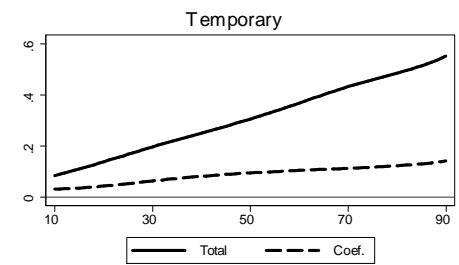

Women
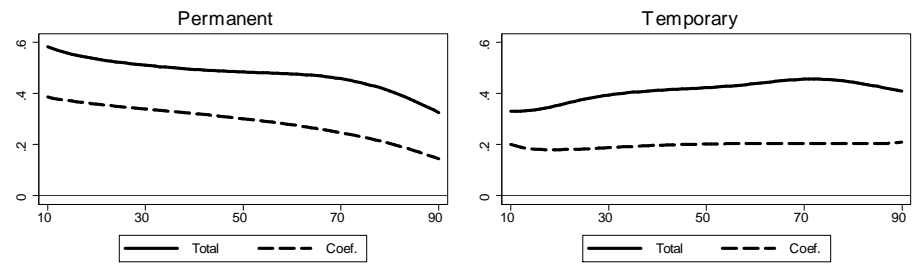

Notes: Whole sample (2005-2012).

\subsection{Results by Region}

Finally, we analyze the regional variation in the average public wage gaps. In particular, we estimate the public-private wage gaps for all the fifteen regions with information available in our dataset (note that there are no data in the MCVL for the Basque Country and Navarra). We think that this exercise is interesting because, in spite of the lack of mobility across Spanish regions, there are substantial differences in their labor market performance (unemployment rates, incidence of temporary contracts...). Moreover, the increasing weight of local corporations' and regional governments' employees in public employment varies substantially across regions (see García-Pérez and Jimeno, 2007). All in all, our aim in this section is to present a descriptive analysis of the regional differences in the public wage gap.

Table 6 reports the estimated gaps (both total and due to returns) at the 25, 50, and 75 percentiles for each region. The highest gaps at the median are observed in Murcia, Canary Islands, and Balearic Islands while Valencia, Cantabria, and Andalusia also present gaps above the national median. On the other hand, the lowest public-private gaps are observed in Extremadura, Madrid, and Aragon. Moreover, the group (and ranking) of median high-gap regions remains similar once we control for observable characteristics and focus in the part of the gap due to returns (coefficients).

Regarding the profiles of the estimated public wage gaps, we observe different patterns across the different regions. The nationwide gaps reported above present an inverted-U shape due mainly to the increasing profile of low-skilled workers combined with the decreasing profiles of medium- and high-skilled workers. Interestingly enough, this aggregate profile is present only in some regions like Castilla and Leon, La Rioja or Valencia where the 25 and 75 percentiles are 
lower than the 50 percentile. Regions such as Aragon, Asturias, Madrid and Catalonia present a decreasing (i.e. Q75 $<$ Q50 $<$ Q25) profile which is similar to the profile observed for mediumand high-skilled workers in the national aggregate. In contrast, other regions such as Andalusia, Balearic Islands, Castilla La Mancha, Extremadura or Murcia, present an increasing profile (i.e. Q75 $>$ Q50 $>$ Q25) similar to that of low-skilled workers. We tentatively argue that these marked differences represent an indication of the heterogeneous composition of the workforce across regions.

Table 6: Estimated gaps by Region

\begin{tabular}{|c|c|c|c|c|c|c|}
\hline & \multicolumn{3}{|c|}{ Total } & \multicolumn{3}{|c|}{ Coef. } \\
\hline & Q25 & Q50 & Q75 & Q25 & Q50 & Q75 \\
\hline Andalusia & 0.38 & 0.46 & 0.49 & 0.28 & 0.30 & 0.30 \\
\hline Aragon & 0.35 & 0.34 & 0.31 & 0.17 & 0.15 & 0.10 \\
\hline Asturias & 0.41 & 0.41 & 0.37 & 0.33 & 0.31 & 0.24 \\
\hline Balearic Islands & 0.47 & 0.53 & 0.57 & 0.27 & 0.32 & 0.33 \\
\hline Canary Islands & 0.50 & 0.55 & 0.59 & 0.35 & 0.39 & 0.36 \\
\hline Cantabria & 0.41 & 0.44 & 0.44 & 0.19 & 0.21 & 0.17 \\
\hline Castilla La Mancha & 0.20 & 0.38 & 0.44 & 0.10 & 0.20 & 0.21 \\
\hline Castilla and Leon & 0.35 & 0.38 & 0.40 & 0.18 & 0.20 & 0.15 \\
\hline Catalonia & 0.41 & 0.41 & 0.35 & 0.23 & 0.23 & 0.18 \\
\hline Extremadura & 0.10 & 0.31 & 0.42 & 0.08 & 0.18 & 0.22 \\
\hline Galicia & 0.36 & 0.42 & 0.46 & 0.24 & 0.26 & 0.22 \\
\hline La Rioja & 0.36 & 0.38 & 0.36 & 0.04 & 0.12 & 0.10 \\
\hline Madrid & 0.39 & 0.34 & 0.22 & 0.25 & 0.21 & 0.12 \\
\hline Murcia & 0.55 & 0.59 & 0.60 & 0.35 & 0.39 & 0.39 \\
\hline Valencia & 0.45 & 0.48 & 0.45 & 0.22 & 0.27 & 0.26 \\
\hline
\end{tabular}

Theoretically, regions with higher unemployment and lower productivity should also present higher public wage gaps. ${ }^{19}$ Figure A.4 in the Appendix presents scatter plots of unemployment and the logarithm of labor productivity against the median public wage gaps for the period 20052012. While the two graphs in levels (upper panel) support the hypothesis discussed above, the bottom panel graphs, which consider 2008-2012 changes instead of levels, illustrate that this association vanishes. Moreover, contrary to the theoretical arguments above, the public wage

\footnotetext{
${ }^{19} \mathrm{~A}$ reduction in productivity or an increase in the unemployment rate should lead to lower wages (see e.g. García-Pérez and Jimeno, 2007); however, since private wages are more responsive to economic conditions than public wages, a deterioration of economic activity (increase in unemployment or reduction in productivity) should generate higher public wage gaps.
} 
gaps have been reduced in all the regions over the 2008-2012 period, characterized by a severe economic recession in Spain. We tentatively conclude that the evolution of the public wage gap in the Spanish regions over the 2008-2012 period was dominated by the recent cuts in public sector wages rather than reductions in private wages in response to the economic downturn.

\section{The Role of Unobservables}

In this section, we analyze the role of workers' unobserved characteristics on both wages and selection into the public sector. A natural concern in the gaps analyzed so far is that workers are not randomly selected into one sector or the other, even after accounting for observed characteristics. Indeed, this concern has been traditionally addressed in the literature by using instrumental variable methods at the mean (see e.g. Moulton, 1990). Alternatively, we rely on the panel dimension of our dataset and take into account the role of unobservables and selection by including individual-specific effects at different points of the wage distribution.

The panel approach to account for selection of workers into the public sector is also advocated by Bargain and Melly (2008) and Campos and Centeno (2012). In these studies, the public-private wage gap is estimated by including a public dummy variable in panel quantile regressions with fixed effects. In contrast, we estimate panel quantile models separately for public and private workers, and we then combine the estimates with the counterfactual distributions approach proposed in CFVM; thus, we allow a more flexible empirical specification with respect to the heterogeneous effects of observable characteristics on wages depending on the sector.

\subsection{Longitudinal Approach}

Public-private wage gaps along the wage distribution are computed on the basis of the CFVM methodology outlined above. However, in order to account for unobserved characteristics possibly affecting both wages and selection, we utilize a different estimation strategy in the first step of the approach. In particular, instead of running standard quantile regressions as in Koenker and Bassett (1978), we consider the fixed effects quantile regression estimator proposed in Canay (2011).

The combination of panel data models with quantile regression represents an open line of research. For instance, Abrevaya and Dahl (2008) consider a correlated random-effects approach, Koenker (2004) treats the individual effects as parameters to be estimated, and, Chernozhukov, Fernandez-Val, Hahn and Newey (2013) consider non-separable models in the individual effects. These estimators are computationally demanding and thus, their combination with the counterfactual distributions approach poses a challenge, especially given the huge sample sizes in the cross-sectional dimension of our dataset. Against this background, Canay (2011) proposes a panel quantile estimator allowing for fixed effects correlated with the regressors that is simple to compute. The key assumption for identification is that the individual effects affect all quantiles in the same way (i.e. the fixed effects are treated as location shift variables); intuitively, if the 
fixed effects are interpreted as a time invariant regressor (e.g. ability), this assumption implies that the coefficient on this regressor is constant across quantiles.

More formally, Canay (2011) considers the following model:

$$
Q_{\theta}\left(y_{i t} \mid X_{i t}\right)=\alpha_{i}+X_{i t} \beta_{\theta}, \theta \in(0,1)
$$

where $X_{i t}$ is the set of covariates and $\alpha_{i}$ represents the individual-specific effect assumed to operate as a simple location shifter of the conditional distribution of $y_{i t}$.

For estimating the model in (9), Canay (2011) proposes a two-step procedure. First, we estimate the individual heterogeneity parameters $\left(\hat{\alpha}_{i}\right)$ using a $\sqrt{N T}$-consistent estimator of $\beta_{\mu}$ in the conditional mean equation for $y_{i t}$ :

$$
\begin{aligned}
y_{i t} & =\alpha_{i}+X_{i t} \beta_{\mu}+v_{i t} \\
\hat{\alpha}_{i} & =T^{-1} \sum_{t=1}^{T}\left[y_{i t}-X_{i t} \hat{\beta}_{\mu}\right]
\end{aligned}
$$

In a second step, the standard quantile regression approach (Koenker and Bassett, 1978) can be applied to the transformed dependent variable $\hat{y}_{i t} \equiv y_{i t}-\hat{\alpha}_{i}$ as follows: ${ }^{20}$

$$
Q_{\theta}\left(\hat{y}_{i t} \mid X_{i t}\right)=X_{i t} \beta_{\theta}
$$

Armed with the fixed effects quantile estimates we can compute the public-private wage gaps following the CFVM approach as described in Section 5.1 and starting from Step 2. In Appendix B.2 we present and discuss these fixed effects quantile coefficient estimates.

\subsection{Results}

We now present the public-private gaps at different points of the wage distribution combining the Canay (2011) panel quantile approach and the CFVM methodology on counterfactual distributions as described above. ${ }^{21}$ Figure 9 shows the observed gaps at different quantiles together with the unexplained gap using quantile regression on pooled data (i.e. assuming exogenous selection into the public sector) and the unexplained gap using fixed effects quantile regression (i.e. allowing for endogenous sector choice on the basis of unobserved characteristics). Interestingly enough, the shape of the public wage mark-up substantially changes once unobserved heterogeneity (i.e. endogenous selection) is accounted for; the decreasing profile for women and the inverted-U-shaped profile for men become roughly flat in both cases, and thus the compression partly disappears after controlling for selection on unobservables.

While Figure 9 graphically illustrates this result, Table 7 reports the estimated public wage premia at different quantiles. In particular, using the pooled approach the public wage markup for men is $0.18,0.26$, and 0.05 at the $10^{t h}, 50^{t h}$, and $90^{\text {th }}$ percentiles respectively, while these figures become $0.072,0.087$ and 0.087 when unobserved heterogeneity is accounted for.

\footnotetext{
${ }^{20}$ See Canay (2011) for a more detailed discussion on the estimator and its asymptotic properties.

${ }^{21}$ These estimates are based on quantile regressions presented in Appendix B.2.
} 
Figure 9: Estimated gaps along the wage distribution
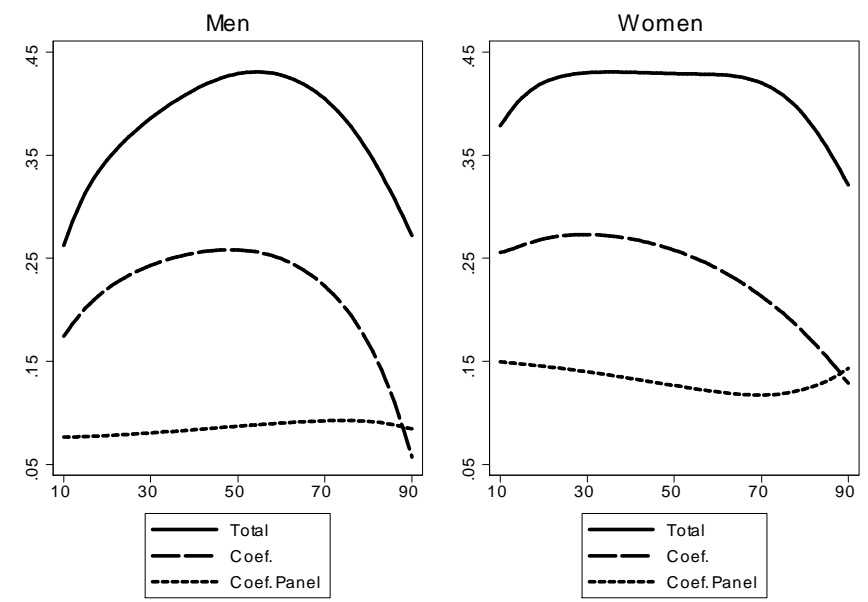

Notes: Whole sample (2005-2012). Individuals with at least 3 observations.

In the case of women, the decreasing profile from the pooled approach is reflected in public wage premia of $0.25,0.25$, and 0.14 at the $10^{t h}, 50^{t h}$, and $90^{t h}$ percentiles respectively, while the profile becomes flat once the fixed effects approach is considered with resulting mark-ups of $0.15,0.13$, and 0.13 .

This finding, also found by Bargain and Melly (2008) for France, cast doubt on the conventional wisdom that the compression of the public wage distribution is due to non-competitive wage settlements. Instead, the higher compression of the wage distribution in the public sector might be explained, at least partially, by selection. Therefore, traditional explanations for the shape and size of the public wage gap (e.g. larger influence of trade unions) should be complemented with the potentially important role of workers' unobserved characteristics, which substantially differ between the public and private sector. Indeed, Figure 10 plot the average at each quantile of the estimated fixed effects for both public and private workers; these estimates clearly point to positive selection of both men and women into the public sector at all the percentiles considered (note that this result does not hold for high-skilled workers as discussed below).

In Figure 11, we present the evolution over time of the public wage gaps discussed above for the whole sample period. First, the lower public pay gaps in 2012 with respect to 2008 are evident for both men and women mostly due to cuts in public wages during the crisis. Second, a decreasing profile arises for men in 2012 (with respect to 2008) once fixed effects are accounted for; we argue that recent across-the-board cuts in public wages might be at the root of this increasing compression in the public wage distribution for men over the 2008-2012 period. 
Table 7: Estimated gaps along the wage distribution

\begin{tabular}{lcccc}
\hline \hline & Quantile & Total & Coef. & Coef. Panel \\
\hline Men & 10 & 0.262 & 0.174 & 0.076 \\
& 25 & 0.368 & 0.233 & 0.079 \\
& 50 & 0.429 & 0.258 & 0.087 \\
& 75 & 0.383 & 0.200 & 0.093 \\
& 90 & 0.272 & 0.057 & 0.085 \\
\hline \multirow{6}{*}{ Women } & 10 & 0.378 & 0.256 & 0.149 \\
& 25 & 0.427 & 0.272 & 0.143 \\
& 50 & 0.429 & 0.258 & 0.127 \\
& 75 & 0.408 & 0.196 & 0.119 \\
& 90 & 0.321 & 0.129 & 0.143 \\
\hline
\end{tabular}

Notes: Whole period (2005-2012). Individuals with

at least 3 observations. Total $=\hat{q}_{\theta_{j}}^{1}-\hat{q}_{\theta_{j}}^{0}$; Coefficients

$=\hat{q}_{\theta_{j}}^{1}-\hat{q}_{\theta_{j}}^{c}$; Coef. Panel $=\hat{q}_{\theta_{j}}^{1}-\hat{q}_{\theta_{j}}^{c}$, with $\hat{y}_{i t}$.

Figure 10: Estimated fixed effects along the wage distribution
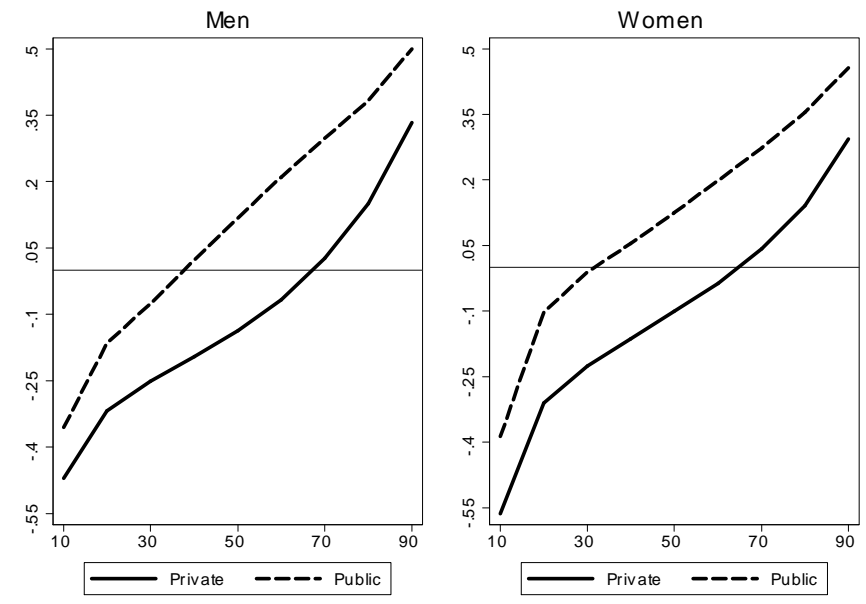

Notes: Average fixed effects at differrent quantiles over the whole sample 2005-2012. Individuals with at least 3 observations. 
Figure 11: Estimated gaps: 2008 vs 2012
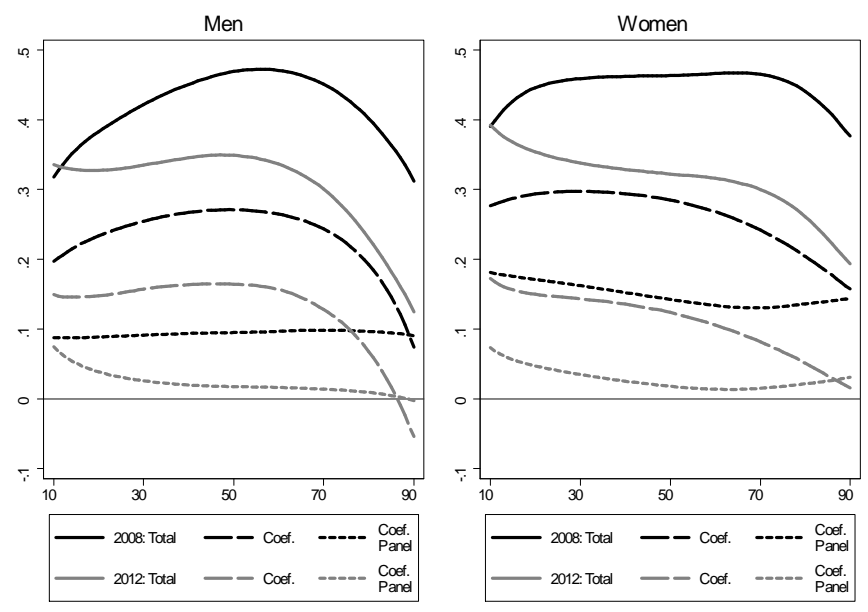

Notes: Individuals with at least 3 observations.

\subsection{Results by Subgroups of Workers}

Figure 12 shows the percentiles of the public sector wage gaps by gender and skill level. Solid, dashed, and dotted lines correspond to total gaps, gaps once observed characteristics are accounted for, and gaps once endogenous selection into the public sector is accounted for, respectively. The non-standard results discussed above (i.e. the increasing profile of the wage gap for low-skilled workers) disappear once we account for unobserved heterogeneity simultaneously affecting selection into the public sector and wages. Indeed, in all cases, the profile of the wage gap becomes roughly flat confirming that the compression in the public wage distribution partly disappears after controlling for selection on unobservables.

Interestingly enough, our results point to positive selection into the public sector for mediumand low-skilled workers but also indicate negative selection for high-skilled workers at the top of the wage distribution. Figure 13 illustrates this finding; the estimated fixed effects for highskilled public workers are lower than those for their private-sector counterparts at the top of the distribution. One possible interpretation would be that the negative selection at the top is the result of the inability of the public sector to retain the most skilled workers. The scarcity of explicit incentives (i.e. performance-based mechanisms) in the public sector might be at the root of this incapacity to retain the most skilled workers. For instance, Burgess and Ratto (2003) review international evidence and find that explicit incentives, and especially payments depending on performance, are typically under-used in the public sector. However, other explanations might also be possible. Differences across the estimated fixed effects for highskilled workers may be the result of differences in laziness between public and private workers that depend on the skill level as found by Dur and Zoutenbier (2014), or differences in risk aversion between private and public workers as documented by Bonin et al. (2007). 
Figure 12: Estimated gaps over the distribution by skill level
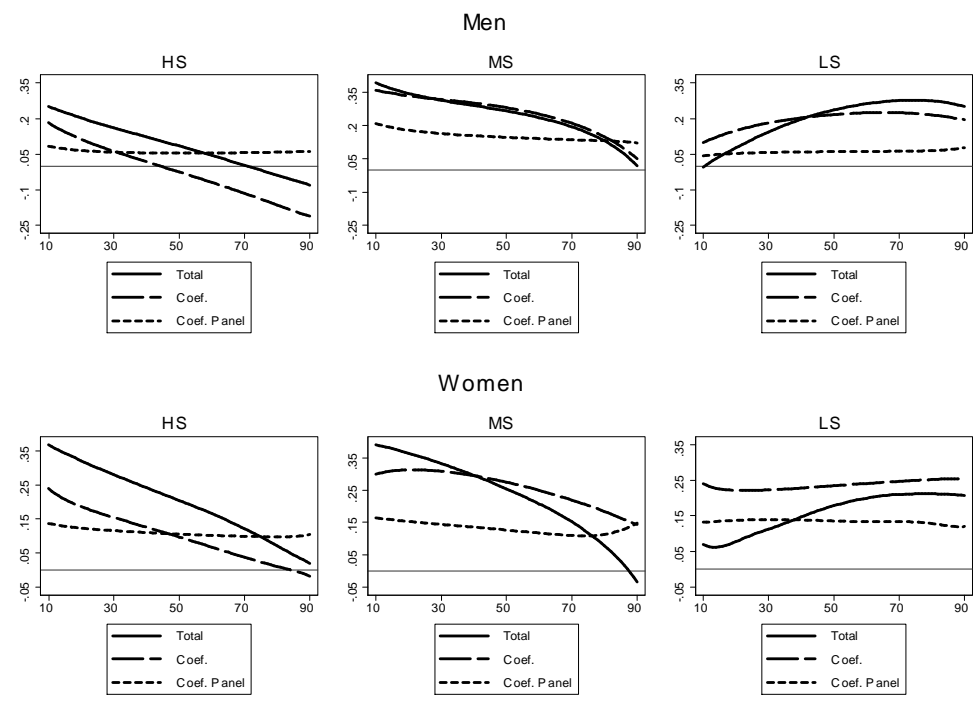

Notes: Whole sample (2005-2012). Individuals with at least 3 observations.

Figure 13: Estimated fixed effects along the wage distribution for high-skilled workers
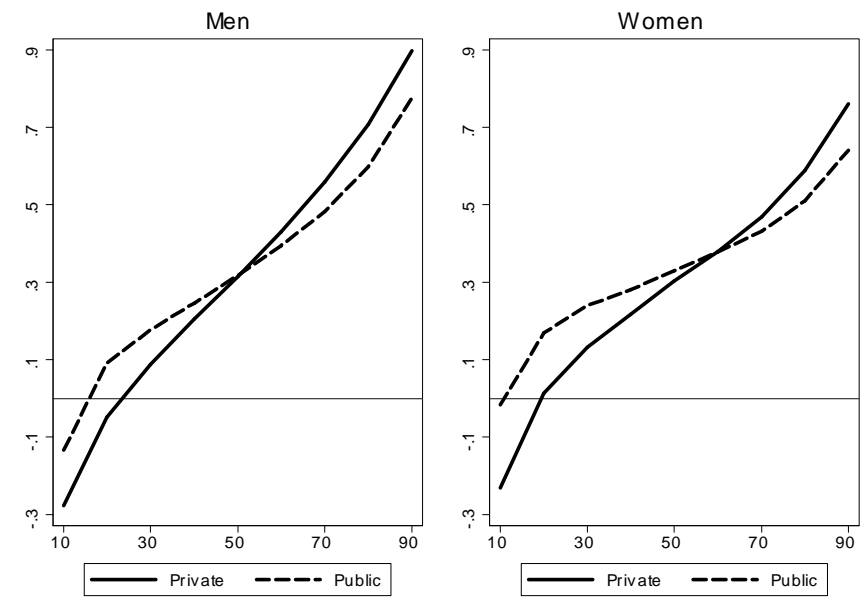

Notes: Average fixed effects at differrent quantiles over the whole sample 2005-2012. Individuals with at least 3 observations. 
Analogously to Figure 12, Figure 14 presents the results by type of contract. As before, accounting for observed characteristics on pooled data (i.e. under the assumption of exogenous selection into the public sector) results in a decreasing profile of the wage gap for permanent workers and a slightly increasing pattern for temporary workers. In line with the flattening of the gaps estimated above when accounting for worker-specific unobserved characteristics, both temporary and permanent workers present a lower and flatter wage gap once endogenous selection is taken into account. While in both cases there is evidence of positive selection into the public sector, this result appears to be more marked in the case of permanent workers.

Figure 14: Estimated gaps over the distribution by type of contract

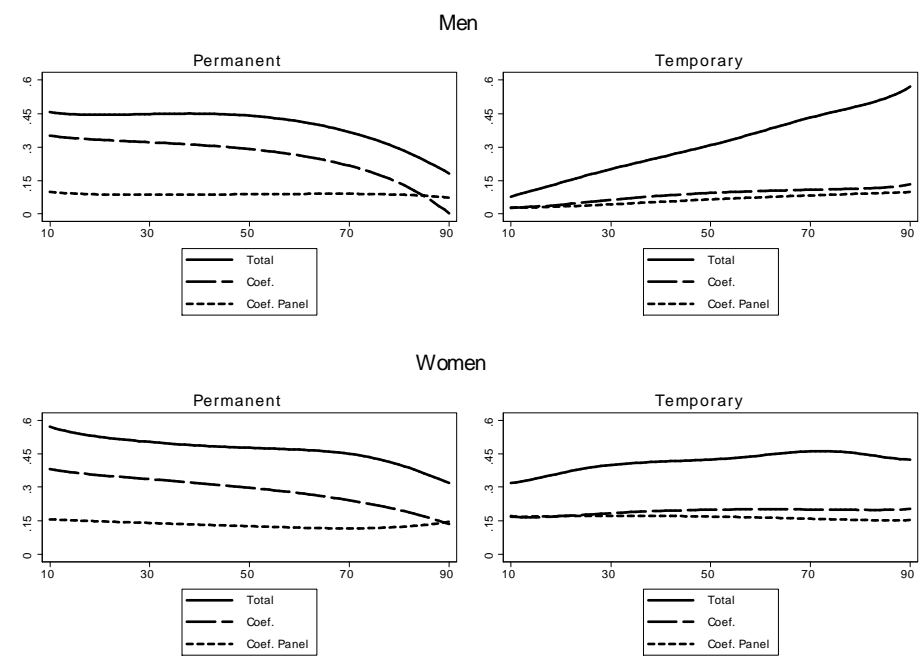

Notes: Whole sample (2005-2012). Individuals with at least 3 observations.

\subsection{Results by Region}

Finally, we analyze the relationship between public wage gaps accounting for selection and regional economic activity in Figure 15 of the Appendix (gap in the median). The positive (negative) association in levels between wage gaps and unemployment (productivity) remains present once endogenous selection is accounted for. However, only the wage gap - unemployment relationship survives when considering changes instead of levels. This finding is in sharp contrast with the lack of correlation between changes in the case of gaps under exogenous selection (see Figure A.4). We argue that selection on unobservables played a role in the adjustment of wages during the crisis. For instance, regions with higher increases in unemployment are those with higher increases in the gap when unobserved characteristics are accounted for; one possible rationale for this result is that composition effects in terms of unobservables (e.g. ability) have resulted in lower private wages in those regions more affected by the rise of unemployment during the crisis. 
Figure 15: Public wage gaps and economic activity across Spanish regions (panel)
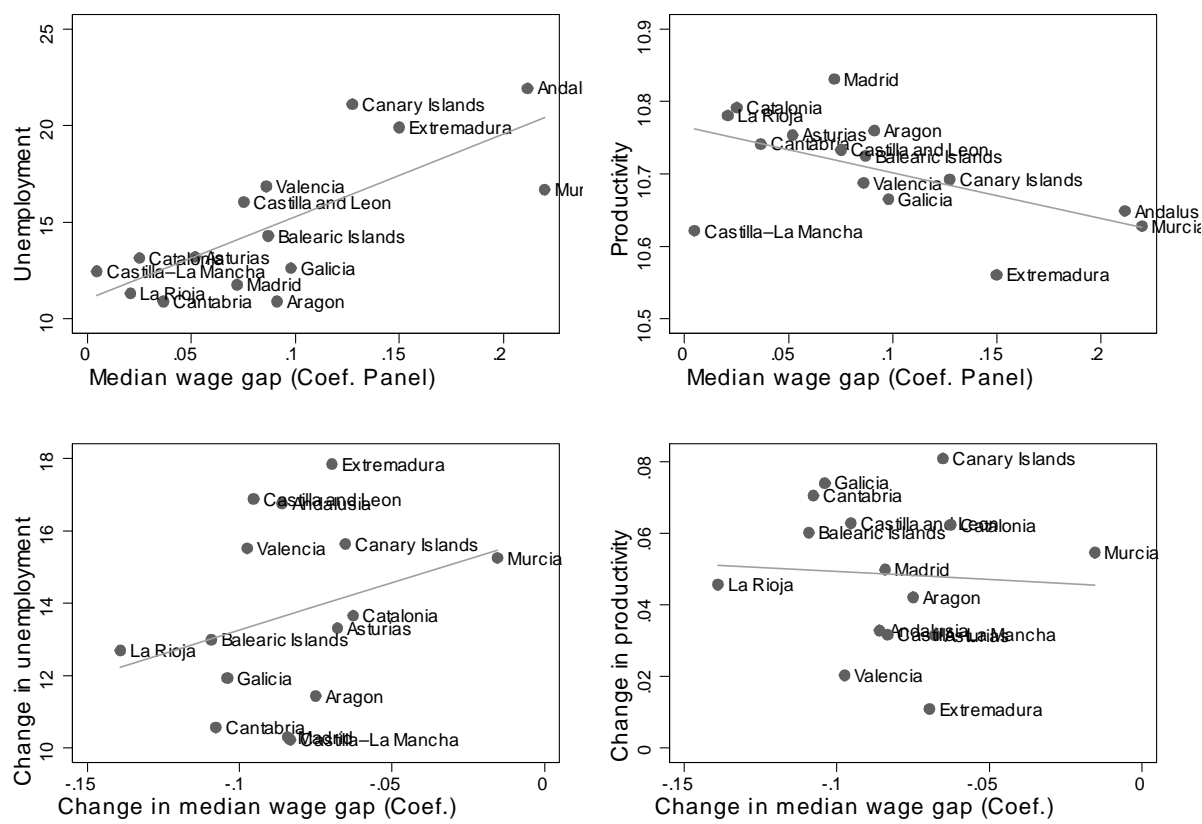

The plots in the upper panel refer to levels for the whole period (2005-2012) while the bottom panel plots refer to changes between 2008 and 2012. Productivity refers to log labor productivity from National Accounts.

\section{Concluding Remarks}

In this paper, we use recently released social security data to analyze the public-private wage gap in Spain. We estimate wage distributions in the presence of covariates separately for men and women in the public sector and in the private sector. Moreover, we take advantage of the longitudinal structure of the data to control for endogenous selection into the public sector. Armed with these estimates, we decompose the public sector wage gap along the wage distribution and isolate the part due to differences in the remunerations of both observable and time-invariant unobserved characteristics.

We find a positive public wage premium for men and women even after accounting for characteristics and endogenous selection; the observed average gap in hourly wages, of around $35 \%$, is reduced to $20 \%$ when accounting for observed characteristics, and to $10 \%$ once endogenous selection is also taken into consideration. We also find substantial variation in the public premium along the wage distribution once observed characteristics are accounted for. However, this variation is partially offset by different patterns of selection into the public sector, which generate a higher compression of the public wage distribution. Indeed, while we generally observe positive selection into the public sector, high-skilled workers at the top of the distribution select negatively; this negative selection at the top might reflect the inability of the public sector to retain the most skilled workers due to the absence of performance-based mechanisms. 


\section{References}

[1] Abrevaya, J. and C. Dahl (2008) "The effects of birth inputs on birthweight: evidence from quantile estimation on panel data", Journal of Business and Economic Statistics, vol. 26(4), pp. 379-397.

[2] Anghel, B., S. de la Rica, and J. Dolado (2011) "The Effect of Public Sector Employment on Women's Labour Martket Outcomes", FEDEA Working Paper No. 2011-08.

[3] Atkinson, A. and J. Micklewright (1983) "On the reliability of income data in the family expenditure survey 1970-1977", Journal of the Royal Statistical Society, vol. 146, pp. 33-61.

[4] Bargain, O. and B. Melly (2008) "Public sector pay gap in France: New evidence using panel data", Discussion Paper Series, IZA DP, No. 3427.

[5] Blinder, A. (1973) "Wage Discrimination: Reduced Form and Structural Estimates", Journal of Human Resources, vol. 8, pp. 436-455.

[6] Bonin, H., T. Dohmen, A. Falk, D. Huffman, and U. Sunde (2007) "Cross-sectional earnings risk and occupational sorting: The role of risk attitudes", Labour Economics vol. 14, pp. 926-937.

[7] Borjas, G. (2002) "The Wage Structure and the Sorting of Workers into the Public Sector", NBER Working Paper No. 9313.

[8] Boyle, G., R. McElligott and J. O'Leary (2004) "Public-private wage differentials in Ireland, 1994-2001", ESRI Quarterly Economic Commentary, Special Article, Summer, Dublin: The Economic and Social Research Institute.

[9] Buchinsky, M. (1998) "Recent advances in quantile regression models: a practical guideline for empirical research", Journal of Human Resources, vol. 33(1), pp. 88-126

[10] Burgess, S. and M. Ratto (2003) "The Role of Incentives in the Public Sector: Issues and Evidence", Oxford Review of Economic Policy, vol. 19, pp. 285-300.

[11] Cai, L. and A.Y.C. Liu (2011) "Public-Private Sector Wage Gap in Australia: Variation along the Distribution", British Journal of Industrial Relations, 49(2), pp. 362-390.

[12] Campos, M. and C. Pereira (2009) "Wages and incentives in the Portuguese public sector", Economic Bulletin, Banco de Portugal, Summer, pp. 57-77.

[13] Campos, M. and C. Centeno (2012) "Public-Private Wage Gaps in the period prior to the adoption of the Euro: an applivation based on longitudinal data", Banco de Portugal WP 1.

[14] Canay, I.A. (2011) "A Simple Approach to Quantile Regression for Panel Data", The Econometrics Journal, 14 (3), 368-386.

[15] Chernozhukov, V., I. Fernandez-Val, and B. Melly (2013) "Inference on counterfactual distributions", Econometrica, 81 (6), 2205-2268.

[16] Chernozhukov, V., I. Fernandez-Val, J. Hahn, and W. Newey (2013) "Average and Quantile Effects in Nonseparable Panel Models", Econometrica, 81 (2), 535-580.

[17] Cohen, S. and B. Lipstein (1954) "Response Errors in the Collection of Wage Statistics by Mail Questionnaire", Journal of the American Statistical Association, vol. 49, pp. 240-250. 
[18] De Castro, F., M. Salto, and H. Steiner (2013) "The gap between public and private wages: new evidence for the EU", European Economy. Economic Papers 508.

[19] Dur, R. and R. Zoutenbier (2014) "Intrinsic Motivations of Public Sector Employees: Evidence for Germany", IZA Working Paper 8239.

[20] Dustmann, C. and A. Van Soest (1997) "Wage Structures in the Private and Public Sectors in West Germany", Fiscal Studies, vol. 18, pp. 225-247.

[21] Foley, P. and F. O'Callaghan (2009) "Investigating the public-private wage gap in Ireland using data from the National Employment Survey 2007", Statistical and Social Inquiry Society.

[22] García-Pérez, I. and J. Jimeno (2007) "Public Sector Wage Gaps in Spanish Regions", The Manchester School, vol. 75, pp 501-531.

[23] Gardeazabal, J. and A. Ugidos (2004) "More on identification in detailed wage decompositions", Review of Economics and Statistics, vol. 86, pp. 1034-1036.

[24] Giordano, R., D. Depalo, M. Pereira, B. Eugene, E. Papapetrou, J. Perez, L. Reiss, and M. Roter (2011) "The public sector pay gap in a selection of euro area countries" ECB WP Series No. 1406.

[25] Gottschalk, P. and M. Huynh (2010) "Are Earnings Inequality and Mobility Overstated? The Impact of Nonclassical Measurement Error", The Review of Economics and Statistics, vol. 92, pp. 302-315.

[26] Gottschalk, P., E. McEntarfer, and R. Moffitt (2008) "Trends in the Transitory Variance of Male Earnings in the U.S., 1991-2003: Preliminary Evidence from LEHD data", Boston College WP No. 696.

[27] Gregory, R. and J. Borland (1999) "Public Sector Labor Markets", In: Ashenfelter O, Card D (eds.) Handbook of Labor Economics, vol. 3c. Elsevier, Amsterdam, pp. 3573-3630.

[28] Griliches, Z., B. Hall, and J. Hausman (1978) "Missing data and self-selection in large panels", Annales de l'INSEE, vol. 30, pp. 138-176.

[29] Groves, R. (2006) "Nonresponse rates and nonresponse bias in household surveys", Public Opinion Quarterly, vol. 70, pp. 646-675.

[30] Herriot, R. and E. Spiers (1980) "Measuring the Impact on Income Statistics of Reporting Differences Between the Current Population Survey and Administrative Sources", Studies from Interagency Data Linkages, U.S. Department of Health, Education, and Welfare, Social Security Administration, pp. 39-49.

[31] Jürges, H. (2002) "The Distribution of the German Public-Private Wage Gap", LABOUR, vol. 16, pp. 347-381.

[32] Koenker, R. (2004) "Quantile regression for longitudinal data", Journal of Multivariate Analysis, vol. 91, pp. 74-89.

[33] Koenker, R. and G. Bassett (1978) "Regression Quantiles", Econometrica, vol. 46, pp. $33-50$.

[34] Lassibille, R. (1998) "Wage Gaps Between the Public and Private Sectors in Spain", Economics of Education Review, vol. 17, pp. 83-92. 
[35] Lamo, A., J. Perez, and L. Schuknecht (2012) "Public or private sector wage leadership? An international perspective", Scandinavian Journal of Economics, vol. 144, pp. 228-244.

[36] Mellow, W. and H. Sider (1983) "Accuracy of Response in Labor Market Surveys: Evidence and Implications", Journal of Labor Economics, vol. 1, pp. 331-344.

[37] Melly, B. (2005) "Public-private sector wage differentials in Germany: Evidence from quantile regression", Empirical Economics, Vol. 30, pp. 505-520.

[38] Miller, H. and L. Paley (1958) "Income Reported in the 1950 Census and on Income Tax Returns. An Appraisal of the 1950 Census Income Data", Princeton, NJ: Princeton University Press, pp. 179-201.

[39] Moulton, B. (1990) "A Re-examination of the Federal-Private wage differential in the United States", Journal of Labor Economics, vol. 8, pp. 270-293.

[40] Mueller, R. E. (1998) "Public-private sector wage differentials in Canada: Evidence from quantile regressions", Economics Letters, vol. 60(2), pp. 229-235.

[41] Nielsen, H. and M. Rosholm (2001) "The Public-Private Sector Wage Gap in Zambia in the 1990s: A Quantile Regression Approach", Empirical Economics, vol. 26, pp. 169-182.

[42] Oaxaca, R. (1973) "Male-Female Wage Differentials in Urban Labor Markets", International Economic Review, vol. 14, pp. 693-709.

[43] Panizza, U. and C. Qiang (2005) "Public-private wage differential and gender gap in Latin America: Spoiled bureaucrats and exploited women?" , The Journal of Socio-Economics, vol. 34, pp. 810-833.

[44] Papapetrou, E. (2006) "The public-private sector pay differential in Greece", Public Finance Review, vol. 35(4), pp. 450-473.

[45] Portnoy, S. (1991) "Asymptotic Behavior of the Number of Regression Quantile Breakpoints", SIAM Journal of Scientific and Statistical Computing, vol. 12, pp. 867-883.

[46] Poterba, J. and K. Rueben (1995) "The Distribution of Public Sector Wage Premia: New Evidence Using Quantile Regression Methods", NBER Working Paper No. 4734.

[47] Rahona, M., M. Salinas, and I. Murillo (2013) "Análisis de los diferenciales salariales por sector y género en España", mimeo.

[48] Ramos, R., E. Sanromá, and H. Simón (2014) "Public-Private Sector Wage Differentials by Type of Contract: Evidence from Spain", IZA Working Paper 8158.

[49] Reder, M. (1975) "The theory of employment and wages in the public sector", in D. Hamermesh (ed.) Labour in the Public and Nonprofit Sectors, Princeton University Press, Princeton, pp. 1-48.

[50] Smith, S. (1976) "Pay differentials between federal government and private sectors workers", Industrial and Labour Relations Review, vol. 29, pp. 233-257.

[51] Zweimuller, J. (1992) "Survey non-response and biases in wage regressions", Economics Letters, vol. 39, pp. 105-109. 


\section{A Additional information}

Table A.1: Sample composition

\begin{tabular}{lcccccc}
\hline \hline & \multicolumn{2}{c}{ All } & \multicolumn{2}{c}{ Men } & \multicolumn{2}{c}{ Women } \\
\cline { 2 - 7 } & Ind. & Obs. & Ind. & Obs. & Ind. & Obs. \\
\hline Prime-age individuals & 716,849 & $4,104,325$ & 381,469 & $2,190,930$ & 335,380 & $1,913,395$ \\
Prime-age working individuals & 716,717 & $3,662,613$ & 381,382 & $1,978,171$ & 335,335 & $1,684,442$ \\
Merged with hours data & 688,607 & $3,232,618$ & 366,034 & $1,762,899$ & 322,573 & $1,469,719$ \\
With at least 3 observations per individual & 505,818 & $2,965,925$ & 273,330 & $1,627,972$ & 232,488 & $1,337,953$ \\
\hline Notes: Whole sample (2005-2012). Ind. = Individuals; Obs. = Observations. & & & \\
\hline \hline
\end{tabular}

Table A.2: Summary statistics

\begin{tabular}{lcccccc}
\hline \hline & \multicolumn{5}{c}{ Public } & \multicolumn{3}{c}{ Private } \\
\cline { 2 - 7 } & All & Men & Women & All & Men & Women \\
\hline Age & 40.45 & 40.76 & 40.26 & 37.20 & 37.63 & 36.63 \\
High-skilled & 38.21 & 32.96 & 41.56 & 12.78 & 13.35 & 12.01 \\
Medium-skilled & 38.75 & 37.81 & 39.35 & 33.86 & 23.11 & 48.31 \\
Low-skilled & 23.03 & 29.22 & 19.09 & 53.35 & 63.54 & 39.68 \\
Tenure & 4.75 & 5.60 & 4.22 & 4.01 & 4.33 & 3.58 \\
Temporary & 46.85 & 36.11 & 53.70 & 31.17 & 32.16 & 29.84 \\
Part-time & 5.48 & 2.70 & 7.25 & 15.48 & 4.66 & 30.02 \\
\hline Days of work & 299.86 & 311.06 & 292.71 & 295.72 & 300.27 & 289.60 \\
Hours worked & 7.33 & 7.52 & 7.21 & 7.65 & 8.24 & 6.85 \\
\hline Annual earnings & 25.90 & 29.17 & 23.82 & 19.39 & 22.41 & 15.32 \\
Daily earnings & 85.65 & 93.69 & 80.51 & 67.34 & 77.37 & 53.87 \\
Hourly wages & 11.81 & 12.56 & 11.32 & 8.97 & 9.60 & 8.11 \\
\hline Notes: Whole sample (2005-2012). Standard deviations of non-binary variables \\
in parentheses. Annual earnings in thousands EUR 2012. \\
\hline \hline
\end{tabular}


Figure A.1: Estimated gaps along the wage distribution
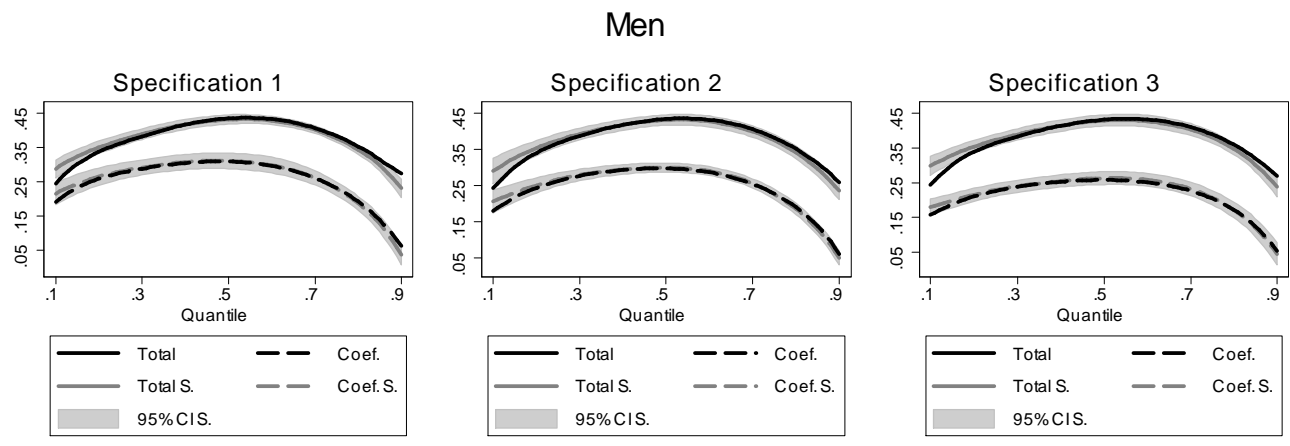

\section{Women}
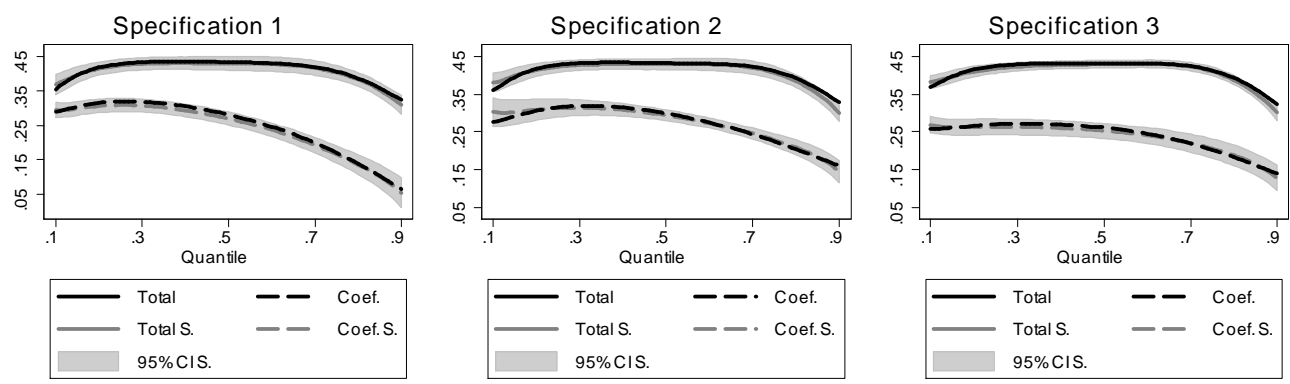

Notes: Whole sample (2005-2012).

Figure A.2: Estimated gaps by skill level: 2008 vs 2012

Men
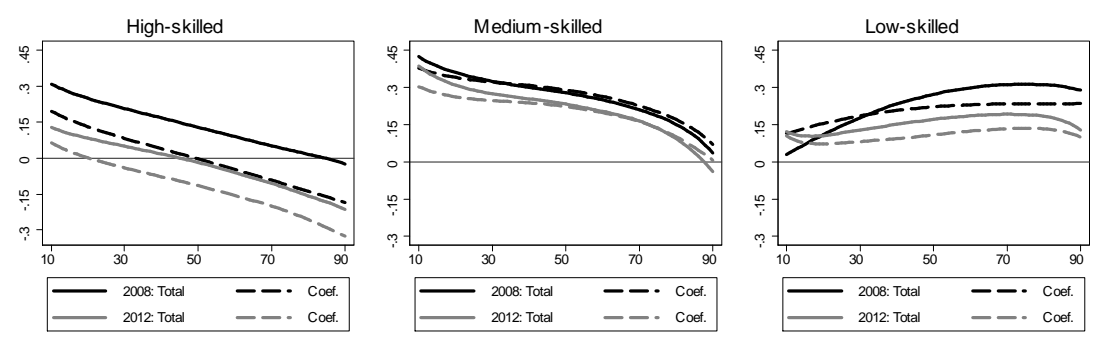

\section{Women}
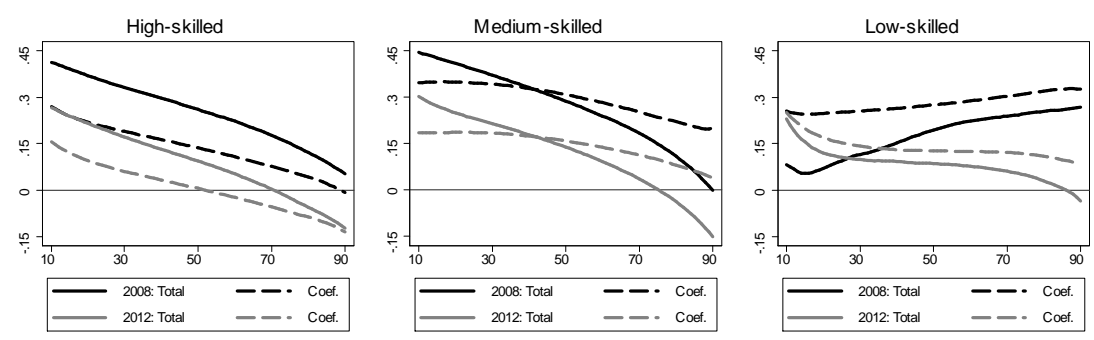
Figure A.3: Estimated gaps by type of contract: 2008 vs 2012

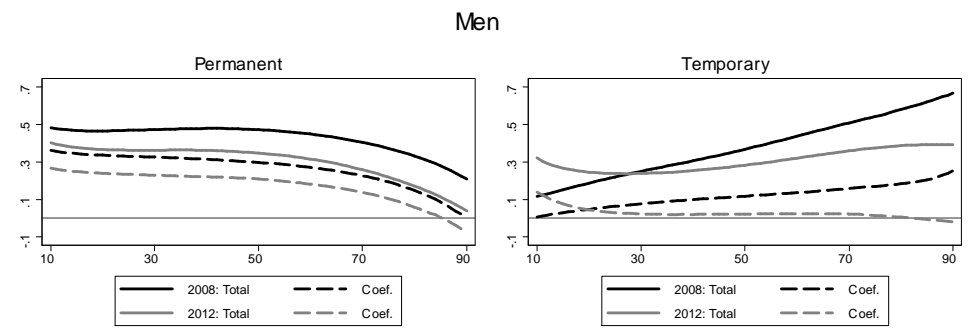

Women
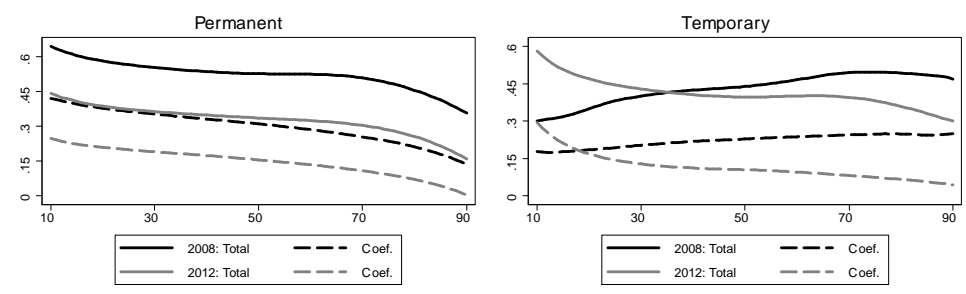

Figure A.4: Public wage gaps and economic activity across Spanish regions (pooled)
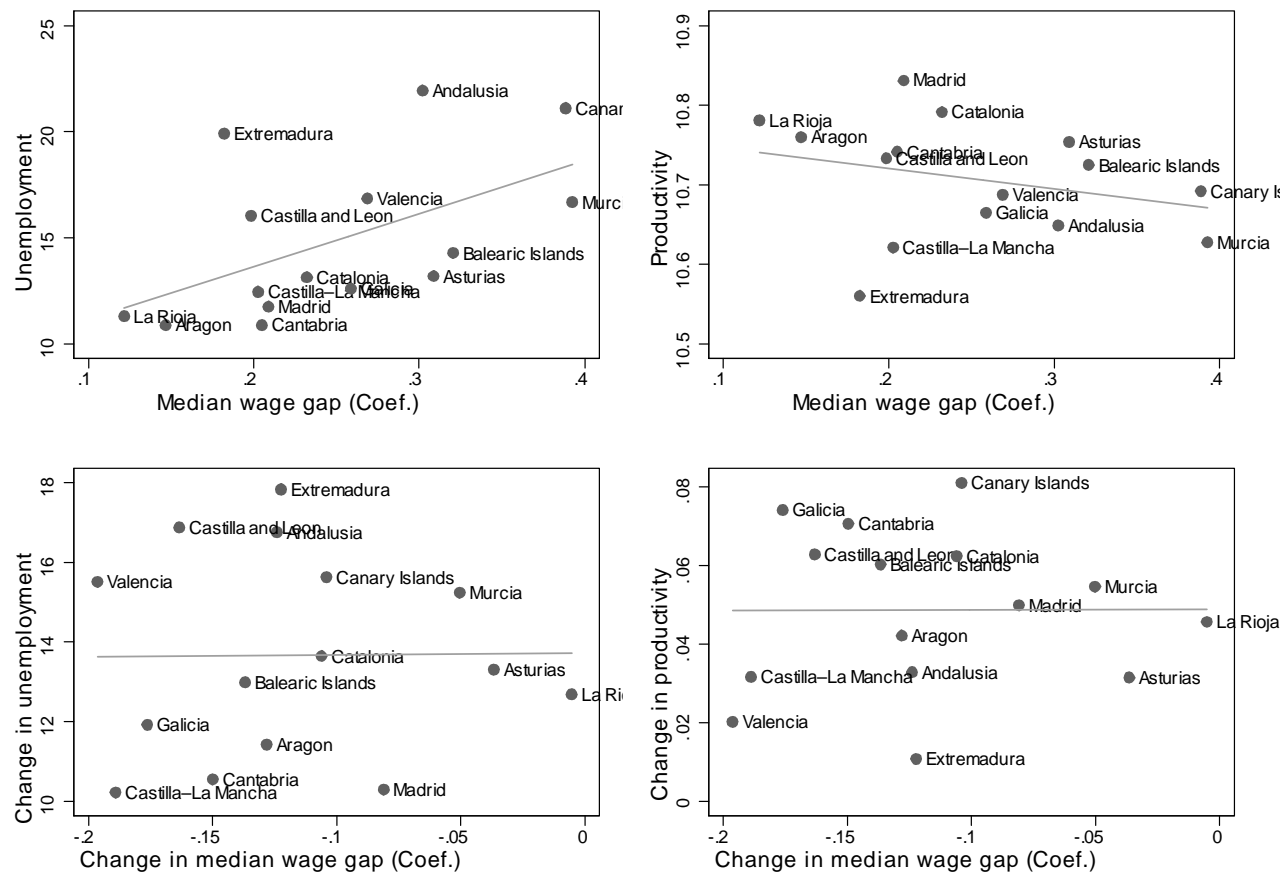

The plots in the upper panel refer to levels for the whole period (2005-2012) while the bottom panel plots refer to changes between 2008 and 2012. Productivity refers to log labor productivity from National Accounts. 


\section{B Quantile Regression Coefficients}

In this Appendix, we present some estimates of the quantile regression coefficients for each group - public and private - based on both pooled and panel approaches. These pooled and fixed-effects quantile regressions represent the first step in the counterfactual decompositions reported in subsections 5.2 and 6.2 , respectively.

\section{B.1 Pooled Quantile Regressions}

Our dependent variable $\left(y_{i}\right)$ is individual $i$ 's log hourly wage in real terms. With respect to the vector of covariates $\left(X_{i}\right)$, we consider three different specifications: first, we consider those variables often included in Mincerian models, namely, age, age squared, skill-groups, time and regional dummies; second, we add indicators for tenure in the firm (less than 1 year, between 1 and 2 years, between 2 and 4, between 4 and 7, between 7 and 15, and more than 15 years), the type of contract (fixed-term vs. open-ended), and the type of work schedule (full-time vs. part-time); and finally, we also include firm size as an additional categorical variable (less than 10 employees, 10-50, 50-200, more than 200).

We present estimates of quantile regression coefficients by gender for selected quantiles, a particular specification and for the pooled sample of the whole period 2005-2012. We have conducted separate quantile regressions for every year as well. Results in coefficient estimates do not change much when we consider different years, or alternative specifications. ${ }^{22}$

In particular, Table B.1 presents the estimation results for specification 3 and five different quantiles - 10th, 25th, 50th, 75th, and 90th - of the wage distribution for private (columns 1-5) and public (columns 6-10) male workers. Similarly, Table B.2 presents the estimation results for females.

The age-earnings profiles are concave both in the public and the private sectors (only the top quantiles for women in the public sector do not present such a concave profile).

We now analyze the differences in "returns to schooling" across the wage distribution in both the private and the public sector. Our coefficient estimates, both for males and females, point to one striking difference between the public and the private sector; while the return to education in general increases with the quantile considered in the private sector, this is not the case in the public sector. This also implies that only at the top of the distribution returns to education are higher in the private sector (competitive) than in the public sector (non-competitive). In contrast, at the bottom of the distribution the return to education is always higher in the public sector. We also find that in the private sector, the profile of returns for low-skilled positions is flatter relative to high and medium-skilled jobs. In addition, for women in the private sectors the profile of returns is less steep than the one for men. In fact, for women in low skilled occupations the return to education also decreases with the quantile in the private sector.

The effect of working part-time on hourly wages is generally positive and, for women, slightly larger in the public sector. ${ }^{23}$ On the other hand, temporary contracts in the private sector have a wage penalty for men, whereas for women the penalty is only present in the bottom-half of the distribution. For females with a temporary contract in the private sevtor, the wage premium in the upper-part increases along the wage distribution, reaching a maximum of $15.1 \%$ at the 90th percentile. In contrast, workers - both men and women - with a temporary contract earn significantly less than permanent workers in the public sector at all quantiles.

Regarding firm size, we find negative wage effects of working in smaller firms both in the private and in the public sector. However those penalties increase along the wage distribution

\footnotetext{
${ }^{22}$ They are available upon request.

${ }^{23}$ Only at the 10 th quantile the part-time effect is negative in both sectors.
} 
in the private sector, whereas in the public sector the penalty is less as we move up in the distribution.

Finally, the last row in Tables B.1 and B.2 presents the p-values of a joint test of all publicprivate interactions, clearly pointing to the existence of a different wage determination process in the public sector.

\section{B.2 Quantile Regressions with Fixed Effects}

We consider the same Mincer-type equation by quantile as in the previous section but accounting for individual-specific effects à la Canay (2011) - see section 6.1 for more details. In order to facilitate the comparison, Tables B.3 and B.4 are analogous to Tables B.1 and B.2 above, but they report coefficient estimates once fixed effects are accounted for.

The age profile is still concave in all cases but decreasing returns begin earlier once unobserved heterogeneity is taken into account. Moreover, the increasing age-returns last longer in the private sector. For instance, for males at the 50th percentile the maximum is reached at 41 years in the private sector, while their public counterparts reach the maximum at the age of 36 years; these figures are 77 and 50 for females in the private and public sectors.

Turning to "returns to schooling" the magnitude of the schooling premium is always smaller once unobserved heterogeneity is accounted for. For instance, the premium for group 1 (with respect to group 10, the omitted category) male workers in the private sector is $86.7 \%$ at the 50 th percentile in the pooled case, while it is only $24.9 \%$ once fixed effects are included in the model; these premia in the public sector are $76.8 \%$ and $31.4 \%$ respectively. Interestingly enough, the striking difference between public and private returns' profile along the wage distribution remains unaltered: while the return to education in general increases with the quantile considered in the private sector, this is not the case in the public sector. However, in contrast to the pooled specification, returns to schooling are generally larger in the public sector, even at the top of the wage distribution; this difference between pooled and fixed effects estimates might be at the root of the flatter wage gaps estimated under the fixed effects specification.

The effect of working part-time is now positive in all cases while it was negative for males and females at the bottom of the distribution. Moreover, the part-time effect is always larger once fixed effects are accounted for. One rationale for this finding is that the prevalence of part-time contracts is substantially higher among workers with lower fixed effects.

Finally, the effects of tenure and size firm are always smaller in magnitude using the fixed effects specification, but the profiles along the distribution as well as the differences between public and private sectors remain the same as in the pooled specification discussed above. 
Table B.1: Quantile regression estimates for public and private sectors - Men

\begin{tabular}{|c|c|c|c|c|c|c|c|c|c|c|}
\hline & \multicolumn{5}{|c|}{ Private Sector } & \multicolumn{5}{|c|}{ Public Sector } \\
\hline & Q10 & Q25 & Q50 & Q75 & Q90 & Q10 & Q25 & Q50 & Q75 & Q90 \\
\hline & (1) & $(2)$ & (3) & (4) & (5) & (6) & (7) & (8) & (9) & (10) \\
\hline \multirow[t]{2}{*}{ Age } & 0.007 & 0.007 & 0.007 & 0.008 & 0.015 & 0.019 & 0.011 & 0.007 & 0.010 & 0.019 \\
\hline & $(0.001)$ & $(0.000)$ & $(0.000)$ & $(0.001)$ & $(0.001)$ & $(0.002)$ & $(0.001)$ & $(0.001)$ & $(0.002)$ & $(0.002)$ \\
\hline \multirow[t]{2}{*}{$(\text { Age } / 100)^{2}$} & -0.006 & -0.005 & -0.003 & -0.002 & -0.008 & -0.018 & -0.010 & -0.006 & -0.009 & -0.018 \\
\hline & $(0.001)$ & $(0.001)$ & $(0.001)$ & $(0.001)$ & $(0.001)$ & $(0.002)$ & $(0.002)$ & $(0.002)$ & $(0.002)$ & $(0.003)$ \\
\hline \multirow[t]{2}{*}{ Group 1} & 0.650 & 0.721 & 0.867 & 1.075 & 1.290 & 0.730 & 0.732 & 0.768 & 0.867 & 0.933 \\
\hline & $(0.003)$ & $(0.002)$ & $(0.002)$ & $(0.002)$ & $(0.004)$ & $(0.005)$ & $(0.004)$ & $(0.004)$ & $(0.005)$ & $(0.007)$ \\
\hline \multirow[t]{2}{*}{ Group 2} & 0.502 & 0.524 & 0.595 & 0.697 & 0.771 & 0.637 & 0.605 & 0.570 & 0.553 & 0.522 \\
\hline & $(0.003)$ & $(0.002)$ & $(0.002)$ & $(0.003)$ & $(0.005)$ & $(0.006)$ & $(0.004)$ & $(0.004)$ & $(0.005)$ & $(0.008)$ \\
\hline \multirow[t]{2}{*}{ Group 3} & 0.429 & 0.470 & 0.593 & 0.759 & 0.867 & 0.441 & 0.409 & 0.392 & 0.391 & 0.348 \\
\hline & $(0.003)$ & $(0.002)$ & $(0.002)$ & $(0.002)$ & $(0.004)$ & $(0.008)$ & $(0.006)$ & $(0.005)$ & $(0.007)$ & $(0.011)$ \\
\hline \multirow[t]{2}{*}{ Group 4} & 0.296 & 0.322 & 0.427 & 0.553 & 0.644 & 0.411 & 0.420 & 0.455 & 0.444 & 0.425 \\
\hline & $(0.003)$ & $(0.002)$ & $(0.002)$ & $(0.002)$ & $(0.004)$ & $(0.007)$ & $(0.005)$ & $(0.005)$ & $(0.006)$ & $(0.010)$ \\
\hline \multirow{2}{*}{ Group 5} & 0.173 & 0.172 & 0.248 & 0.378 & 0.488 & 0.339 & 0.334 & 0.335 & 0.292 & 0.219 \\
\hline & $(0.002)$ & $(0.001)$ & $(0.001)$ & $(0.002)$ & $(0.003)$ & $(0.005)$ & $(0.004)$ & $(0.004)$ & $(0.005)$ & $(0.008)$ \\
\hline \multirow[t]{2}{*}{ Group 6} & 0.032 & 0.042 & 0.059 & 0.103 & 0.140 & 0.162 & 0.097 & 0.050 & 0.019 & -0.037 \\
\hline & $(0.003)$ & $(0.002)$ & $(0.002)$ & $(0.003)$ & $(0.005)$ & $(0.006)$ & $(0.005)$ & $(0.004)$ & $(0.005)$ & $(0.009)$ \\
\hline \multirow[t]{2}{*}{ Group 7} & 0.033 & 0.018 & 0.055 & 0.144 & 0.250 & 0.284 & 0.241 & 0.236 & 0.259 & 0.199 \\
\hline & $(0.003)$ & $(0.002)$ & $(0.002)$ & $(0.002)$ & $(0.004)$ & $(0.006)$ & $(0.004)$ & $(0.004)$ & $(0.005)$ & $(0.008)$ \\
\hline \multirow[t]{2}{*}{ Group 8} & 0.176 & 0.131 & 0.113 & 0.124 & 0.136 & 0.278 & 0.236 & 0.210 & 0.180 & 0.111 \\
\hline & $(0.002)$ & $(0.001)$ & $(0.001)$ & $(0.001)$ & $(0.002)$ & $(0.005)$ & $(0.004)$ & $(0.004)$ & $(0.005)$ & $(0.008)$ \\
\hline \multirow[t]{2}{*}{ Group 9} & 0.090 & 0.054 & 0.042 & 0.060 & 0.073 & 0.227 & 0.164 & 0.112 & 0.077 & 0.002 \\
\hline & $(0.002)$ & $(0.001)$ & $(0.001)$ & $(0.002)$ & $(0.003)$ & $(0.007)$ & $(0.006)$ & $(0.005)$ & $(0.007)$ & $(0.011)$ \\
\hline \multirow[t]{2}{*}{ Tenure $<1$ year } & -0.391 & -0.318 & -0.282 & -0.257 & -0.144 & -0.320 & -0.272 & -0.202 & -0.095 & 0.139 \\
\hline & $(0.003)$ & $(0.002)$ & $(0.002)$ & $(0.002)$ & $(0.004)$ & $(0.007)$ & $(0.005)$ & $(0.005)$ & $(0.006)$ & $(0.010)$ \\
\hline \multirow[t]{2}{*}{ Tenure 1-2 years } & -0.261 & -0.237 & -0.241 & -0.247 & -0.224 & -0.164 & -0.165 & -0.142 & -0.093 & -0.067 \\
\hline & $(0.003)$ & $(0.002)$ & $(0.002)$ & $(0.002)$ & $(0.004)$ & $(0.007)$ & $(0.005)$ & $(0.005)$ & $(0.006)$ & $(0.010)$ \\
\hline \multirow[t]{2}{*}{ Tenure 2-4 years } & -0.215 & -0.202 & -0.210 & -0.210 & -0.188 & -0.094 & -0.098 & -0.077 & -0.052 & -0.047 \\
\hline & $(0.003)$ & $(0.002)$ & $(0.002)$ & $(0.002)$ & $(0.004)$ & $(0.005)$ & $(0.004)$ & $(0.004)$ & $(0.005)$ & $(0.007)$ \\
\hline \multirow[t]{2}{*}{ Tenure 4-7 years } & -0.165 & -0.156 & -0.164 & -0.162 & -0.143 & -0.078 & -0.068 & -0.047 & -0.034 & -0.035 \\
\hline & $(0.003)$ & $(0.002)$ & $(0.002)$ & $(0.002)$ & $(0.004)$ & $(0.006)$ & $(0.004)$ & $(0.004)$ & $(0.005)$ & $(0.008)$ \\
\hline \multirow[t]{2}{*}{ Tenure $7-15$ years } & -0.096 & -0.090 & -0.094 & -0.092 & -0.080 & -0.032 & -0.030 & -0.018 & -0.018 & -0.032 \\
\hline & $(0.003)$ & $(0.002)$ & $(0.002)$ & $(0.002)$ & $(0.004)$ & $(0.005)$ & $(0.004)$ & $(0.004)$ & $(0.005)$ & $(0.008)$ \\
\hline \multirow[t]{2}{*}{ Part-time } & -0.253 & -0.029 & 0.147 & 0.334 & 0.500 & -0.201 & -0.016 & 0.093 & 0.242 & 0.315 \\
\hline & $(0.002)$ & $(0.002)$ & $(0.002)$ & $(0.002)$ & $(0.004)$ & $(0.008)$ & $(0.006)$ & $(0.006)$ & $(0.007)$ & $(0.012)$ \\
\hline Temporary & 0.057 & 0.065 & 0.053 & 0.036 & 0.030 & -0.206 & -0.169 & -0.173 & -0.177 & -0.144 \\
\hline & $(0.002)$ & $(0.001)$ & $(0.001)$ & $(0.001)$ & $(0.002)$ & $(0.004)$ & $(0.003)$ & $(0.003)$ & $(0.003)$ & $(0.006)$ \\
\hline Size $<10$ employees & -0.263 & -0.256 & -0.271 & -0.269 & -0.241 & -0.075 & -0.084 & -0.095 & -0.086 & -0.047 \\
\hline & $(0.002)$ & $(0.001)$ & $(0.001)$ & $(0.001)$ & $(0.002)$ & $(0.004)$ & $(0.003)$ & $(0.003)$ & $(0.004)$ & $(0.006)$ \\
\hline Size 10-50 employees & -0.199 & -0.209 & -0.226 & -0.221 & -0.211 & -0.083 & -0.066 & -0.046 & -0.022 & 0.024 \\
\hline & $(0.002)$ & $(0.001)$ & $(0.001)$ & $(0.001)$ & $(0.003)$ & $(0.004)$ & $(0.003)$ & $(0.003)$ & $(0.004)$ & $(0.006)$ \\
\hline Size 50-200 employees & -0.098 & -0.095 & -0.097 & -0.088 & -0.087 & -0.033 & -0.037 & -0.030 & -0.020 & 0.001 \\
\hline & $(0.002)$ & $(0.001)$ & $(0.001)$ & $(0.002)$ & $(0.003)$ & $(0.003)$ & $(0.003)$ & $(0.002)$ & $(0.003)$ & $(0.005)$ \\
\hline Constant & 1.481 & 1.672 & 1.851 & 1.960 & 1.963 & 1.258 & 1.614 & 1.881 & 1.986 & 2.011 \\
\hline & $(0.013)$ & $(0.009)$ & $(0.008)$ & $(0.011)$ & $(0.019)$ & $(0.036)$ & $(0.027)$ & $(0.026)$ & $(0.032)$ & $(0.052)$ \\
\hline Pseudo R-squared & 0.148 & 0.169 & 0.226 & 0.266 & 0.258 & 0.334 & 0.309 & 0.289 & 0.251 & 0.237 \\
\hline Joint $\mathrm{p}$-value & 0.00 & 0.00 & 0.00 & 0.00 & 0.00 & & & & & \\
\hline
\end{tabular}


Table B.2: Quantile regression estimates for public and private sectors - Women

\begin{tabular}{|c|c|c|c|c|c|c|c|c|c|c|}
\hline & \multicolumn{5}{|c|}{ Private Sector } & \multicolumn{5}{|c|}{ Public Sector } \\
\hline & Q10 & Q25 & Q50 & Q75 & Q90 & Q10 & Q25 & Q50 & Q75 & Q90 \\
\hline & (1) & $(2)$ & (3) & (4) & (5) & (6) & (7) & (8) & (9) & (10) \\
\hline \multirow[t]{2}{*}{ Age } & 0.011 & 0.015 & 0.018 & 0.021 & 0.029 & 0.018 & 0.013 & 0.012 & 0.010 & 0.002 \\
\hline & $(0.001)$ & $(0.001)$ & $(0.001)$ & $(0.001)$ & $(0.001)$ & $(0.002)$ & $(0.001)$ & $(0.001)$ & $(0.001)$ & $(0.002)$ \\
\hline \multirow[t]{2}{*}{$(\text { Age } / 100)^{2}$} & -0.010 & -0.016 & -0.019 & -0.021 & -0.027 & -0.013 & -0.010 & -0.009 & -0.008 & 0.000 \\
\hline & $(0.001)$ & $(0.001)$ & $(0.001)$ & $(0.001)$ & $(0.001)$ & $(0.002)$ & $(0.001)$ & $(0.001)$ & $(0.001)$ & $(0.002)$ \\
\hline \multirow[t]{2}{*}{ Group 1} & 0.755 & 0.735 & 0.795 & 0.927 & 1.088 & 0.819 & 0.862 & 0.886 & 0.938 & 0.943 \\
\hline & $(0.004)$ & $(0.003)$ & $(0.002)$ & $(0.003)$ & $(0.005)$ & $(0.005)$ & $(0.003)$ & $(0.003)$ & $(0.003)$ & $(0.005)$ \\
\hline \multirow[t]{2}{*}{ Group 2} & 0.619 & 0.588 & 0.634 & 0.662 & 0.711 & 0.730 & 0.749 & 0.715 & 0.633 & 0.520 \\
\hline & $(0.004)$ & $(0.003)$ & $(0.002)$ & $(0.003)$ & $(0.005)$ & $(0.005)$ & $(0.003)$ & $(0.003)$ & $(0.003)$ & $(0.005)$ \\
\hline \multirow[t]{2}{*}{ Group 3} & 0.586 & 0.567 & 0.672 & 0.829 & 0.933 & 0.469 & 0.474 & 0.443 & 0.376 & 0.285 \\
\hline & $(0.005)$ & $(0.003)$ & $(0.003)$ & $(0.003)$ & $(0.005)$ & $(0.008)$ & $(0.005)$ & $(0.005)$ & $(0.006)$ & $(0.009)$ \\
\hline \multirow[t]{2}{*}{ Group 4} & 0.342 & 0.284 & 0.355 & 0.530 & 0.670 & 0.370 & 0.368 & 0.344 & 0.308 & 0.246 \\
\hline & $(0.005)$ & $(0.003)$ & $(0.003)$ & $(0.003)$ & $(0.005)$ & $(0.009)$ & $(0.006)$ & $(0.005)$ & $(0.006)$ & $(0.010)$ \\
\hline \multirow{2}{*}{ Group 5} & 0.360 & 0.279 & 0.292 & 0.351 & 0.445 & 0.380 & 0.398 & 0.366 & 0.284 & 0.169 \\
\hline & $(0.003)$ & $(0.002)$ & $(0.001)$ & $(0.002)$ & $(0.003)$ & $(0.005)$ & $(0.003)$ & $(0.003)$ & $(0.004)$ & $(0.006)$ \\
\hline \multirow[t]{2}{*}{ Group 6} & 0.200 & 0.122 & 0.115 & 0.132 & 0.178 & 0.276 & 0.268 & 0.217 & 0.116 & -0.025 \\
\hline & $(0.004)$ & $(0.003)$ & $(0.002)$ & $(0.003)$ & $(0.005)$ & $(0.006)$ & $(0.004)$ & $(0.003)$ & $(0.004)$ & $(0.006)$ \\
\hline \multirow[t]{2}{*}{ Group 7} & 0.254 & 0.163 & 0.151 & 0.175 & 0.229 & 0.317 & 0.312 & 0.255 & 0.151 & 0.008 \\
\hline & $(0.003)$ & $(0.002)$ & $(0.001)$ & $(0.002)$ & $(0.003)$ & $(0.005)$ & $(0.003)$ & $(0.003)$ & $(0.003)$ & $(0.005)$ \\
\hline \multirow[t]{2}{*}{ Group 8} & 0.225 & 0.139 & 0.118 & 0.101 & 0.095 & 0.252 & 0.260 & 0.259 & 0.196 & 0.087 \\
\hline & $(0.003)$ & $(0.002)$ & $(0.002)$ & $(0.002)$ & $(0.004)$ & $(0.010)$ & $(0.006)$ & $(0.005)$ & $(0.007)$ & $(0.011)$ \\
\hline \multirow[t]{2}{*}{ Group 9} & 0.168 & 0.084 & 0.053 & 0.031 & 0.018 & 0.233 & 0.231 & 0.174 & 0.074 & -0.066 \\
\hline & $(0.003)$ & $(0.002)$ & $(0.002)$ & $(0.002)$ & $(0.003)$ & $(0.008)$ & $(0.005)$ & $(0.004)$ & $(0.006)$ & $(0.009)$ \\
\hline \multirow[t]{2}{*}{ Tenure $<1$ year } & -0.396 & -0.336 & -0.296 & -0.270 & -0.167 & -0.316 & -0.239 & -0.169 & -0.082 & 0.042 \\
\hline & $(0.005)$ & $(0.003)$ & $(0.003)$ & $(0.004)$ & $(0.006)$ & $(0.007)$ & $(0.005)$ & $(0.004)$ & $(0.005)$ & $(0.008)$ \\
\hline \multirow[t]{2}{*}{ Tenure 1-2 years } & -0.304 & -0.285 & -0.273 & -0.274 & -0.245 & -0.239 & -0.180 & -0.160 & -0.129 & -0.108 \\
\hline & $(0.005)$ & $(0.003)$ & $(0.003)$ & $(0.004)$ & $(0.006)$ & $(0.007)$ & $(0.005)$ & $(0.004)$ & $(0.005)$ & $(0.008)$ \\
\hline \multirow[t]{2}{*}{ Tenure 2-4 years } & -0.273 & -0.257 & -0.249 & -0.254 & -0.233 & -0.165 & -0.137 & -0.119 & -0.106 & -0.097 \\
\hline & $(0.005)$ & $(0.003)$ & $(0.003)$ & $(0.003)$ & $(0.006)$ & $(0.007)$ & $(0.004)$ & $(0.004)$ & $(0.005)$ & $(0.008)$ \\
\hline \multirow[t]{2}{*}{ Tenure 4-7 years } & -0.226 & -0.215 & -0.207 & -0.216 & -0.190 & -0.115 & -0.108 & -0.092 & -0.083 & -0.078 \\
\hline & $(0.005)$ & $(0.003)$ & $(0.003)$ & $(0.003)$ & $(0.006)$ & $(0.007)$ & $(0.004)$ & $(0.004)$ & $(0.005)$ & $(0.008)$ \\
\hline \multirow[t]{2}{*}{ Tenure $7-15$ years } & -0.156 & -0.141 & -0.132 & -0.129 & -0.099 & -0.058 & -0.061 & -0.051 & -0.048 & -0.042 \\
\hline & $(0.005)$ & $(0.003)$ & $(0.003)$ & $(0.003)$ & $(0.006)$ & $(0.006)$ & $(0.004)$ & $(0.004)$ & $(0.004)$ & $(0.007)$ \\
\hline \multirow[t]{2}{*}{ Part-time } & -0.116 & 0.032 & 0.159 & 0.263 & 0.327 & -0.040 & 0.037 & 0.151 & 0.295 & 0.424 \\
\hline & $(0.002)$ & $(0.001)$ & $(0.001)$ & $(0.001)$ & $(0.002)$ & $(0.005)$ & $(0.003)$ & $(0.003)$ & $(0.003)$ & $(0.005)$ \\
\hline Temporary & 0.002 & 0.020 & 0.032 & 0.045 & 0.062 & -0.086 & -0.070 & -0.069 & -0.071 & -0.071 \\
\hline & $(0.002)$ & $(0.002)$ & $(0.001)$ & $(0.002)$ & $(0.003)$ & $(0.003)$ & $(0.002)$ & $(0.002)$ & $(0.002)$ & $(0.003)$ \\
\hline Size $<10$ employees & -0.215 & -0.194 & -0.184 & -0.166 & -0.133 & -0.132 & -0.112 & -0.091 & -0.063 & -0.026 \\
\hline & $(0.002)$ & $(0.001)$ & $(0.001)$ & $(0.001)$ & $(0.002)$ & $(0.004)$ & $(0.003)$ & $(0.002)$ & $(0.003)$ & $(0.004)$ \\
\hline Size 10-50 employees & -0.113 & -0.111 & -0.117 & -0.125 & -0.126 & -0.193 & -0.162 & -0.108 & -0.047 & -0.009 \\
\hline & $(0.002)$ & $(0.002)$ & $(0.001)$ & $(0.002)$ & $(0.003)$ & $(0.004)$ & $(0.003)$ & $(0.002)$ & $(0.003)$ & $(0.004)$ \\
\hline Size 50-200 employees & -0.030 & -0.034 & -0.040 & -0.041 & -0.044 & -0.105 & -0.079 & -0.039 & -0.024 & -0.008 \\
\hline & $(0.003)$ & $(0.002)$ & $(0.001)$ & $(0.002)$ & $(0.003)$ & $(0.003)$ & $(0.002)$ & $(0.002)$ & $(0.002)$ & $(0.004)$ \\
\hline Constant & 1.124 & 1.319 & 1.437 & 1.546 & 1.573 & 1.106 & 1.358 & 1.543 & 1.810 & 2.234 \\
\hline & $(0.020)$ & $(0.012)$ & $(0.011)$ & $(0.013)$ & $(0.022)$ & $(0.033)$ & $(0.022)$ & $(0.018)$ & $(0.023)$ & $(0.037)$ \\
\hline Pseudo R-squared & 0.123 & 0.131 & 0.171 & 0.196 & 0.184 & 0.334 & 0.321 & 0.317 & 0.298 & 0.271 \\
\hline Joint $\mathrm{p}$-value & 0.00 & 0.00 & 0.00 & 0.00 & 0.00 & & & & & \\
\hline
\end{tabular}


Table B.3: Quantile regression estimates for public and private sectors - Men

\begin{tabular}{|c|c|c|c|c|c|c|c|c|c|c|}
\hline & \multicolumn{5}{|c|}{ Private Sector } & \multicolumn{5}{|c|}{ Public Sector } \\
\hline & Q10 & Q25 & Q50 & Q75 & Q90 & Q10 & Q25 & Q50 & Q75 & Q90 \\
\hline & (1) & $(2)$ & (3) & (4) & (5) & (6) & (7) & (8) & (9) & (10) \\
\hline \multirow[t]{2}{*}{ Age } & 0.017 & 0.016 & 0.018 & 0.020 & 0.023 & 0.032 & 0.029 & 0.028 & 0.028 & 0.024 \\
\hline & $(0.000)$ & $(0.000)$ & $(0.000)$ & $(0.000)$ & $(0.000)$ & $(0.001)$ & $(0.001)$ & $(0.001)$ & $(0.001)$ & $(0.001)$ \\
\hline \multirow[t]{2}{*}{$(\text { Age } / 100)^{2}$} & -0.021 & -0.020 & -0.022 & -0.026 & -0.030 & -0.043 & -0.040 & -0.039 & -0.040 & -0.036 \\
\hline & $(0.001)$ & $(0.000)$ & $(0.000)$ & $(0.000)$ & $(0.001)$ & $(0.002)$ & $(0.001)$ & $(0.001)$ & $(0.001)$ & $(0.002)$ \\
\hline \multirow[t]{2}{*}{ Group 1} & 0.212 & 0.225 & 0.249 & 0.274 & 0.293 & 0.290 & 0.306 & 0.314 & 0.320 & 0.325 \\
\hline & $(0.002)$ & $(0.001)$ & $(0.001)$ & $(0.001)$ & $(0.002)$ & $(0.004)$ & $(0.002)$ & $(0.001)$ & $(0.002)$ & $(0.004)$ \\
\hline \multirow[t]{2}{*}{ Group 2} & 0.178 & 0.184 & 0.199 & 0.214 & 0.220 & 0.296 & 0.305 & 0.304 & 0.300 & 0.298 \\
\hline & $(0.002)$ & $(0.001)$ & $(0.001)$ & $(0.001)$ & $(0.002)$ & $(0.004)$ & $(0.002)$ & $(0.002)$ & $(0.002)$ & $(0.004)$ \\
\hline \multirow[t]{2}{*}{ Group 3} & 0.158 & 0.162 & 0.180 & 0.198 & 0.204 & 0.216 & 0.213 & 0.209 & 0.202 & 0.191 \\
\hline & $(0.002)$ & $(0.001)$ & $(0.001)$ & $(0.001)$ & $(0.002)$ & $(0.005)$ & $(0.003)$ & $(0.002)$ & $(0.003)$ & $(0.005)$ \\
\hline \multirow[t]{2}{*}{ Group 4} & 0.136 & 0.129 & 0.133 & 0.139 & 0.141 & 0.241 & 0.229 & 0.219 & 0.210 & 0.197 \\
\hline & $(0.002)$ & $(0.001)$ & $(0.001)$ & $(0.001)$ & $(0.002)$ & $(0.005)$ & $(0.003)$ & $(0.002)$ & $(0.003)$ & $(0.005)$ \\
\hline \multirow{2}{*}{ Group 5} & 0.083 & 0.079 & 0.086 & 0.092 & 0.096 & 0.256 & 0.243 & 0.228 & 0.212 & 0.192 \\
\hline & $(0.002)$ & $(0.001)$ & $(0.001)$ & $(0.001)$ & $(0.002)$ & $(0.004)$ & $(0.002)$ & $(0.002)$ & $(0.002)$ & $(0.004)$ \\
\hline \multirow[t]{2}{*}{ Group 6} & 0.005 & 0.001 & 0.010 & 0.020 & 0.019 & 0.182 & 0.167 & 0.150 & 0.132 & 0.109 \\
\hline & $(0.002)$ & $(0.001)$ & $(0.001)$ & $(0.001)$ & $(0.002)$ & $(0.004)$ & $(0.002)$ & $(0.002)$ & $(0.002)$ & $(0.004)$ \\
\hline \multirow[t]{2}{*}{ Group 7} & -0.008 & -0.009 & -0.000 & 0.009 & 0.014 & 0.183 & 0.171 & 0.157 & 0.142 & 0.127 \\
\hline & $(0.002)$ & $(0.001)$ & $(0.001)$ & $(0.001)$ & $(0.002)$ & $(0.004)$ & $(0.002)$ & $(0.002)$ & $(0.002)$ & $(0.004)$ \\
\hline \multirow[t]{2}{*}{ Group 8} & 0.086 & 0.069 & 0.064 & 0.060 & 0.051 & 0.125 & 0.115 & 0.101 & 0.089 & 0.074 \\
\hline & $(0.001)$ & $(0.001)$ & $(0.000)$ & $(0.001)$ & $(0.001)$ & $(0.004)$ & $(0.002)$ & $(0.002)$ & $(0.002)$ & $(0.004)$ \\
\hline \multirow[t]{2}{*}{ Group 9} & 0.045 & 0.033 & 0.029 & 0.027 & 0.020 & 0.124 & 0.110 & 0.092 & 0.072 & 0.050 \\
\hline & $(0.001)$ & $(0.001)$ & $(0.001)$ & $(0.001)$ & $(0.001)$ & $(0.005)$ & $(0.003)$ & $(0.002)$ & $(0.003)$ & $(0.005)$ \\
\hline \multirow[t]{2}{*}{ Tenure $<1$ year } & -0.343 & -0.222 & -0.125 & -0.042 & 0.072 & -0.253 & -0.131 & -0.027 & 0.072 & 0.230 \\
\hline & $(0.002)$ & $(0.001)$ & $(0.001)$ & $(0.001)$ & $(0.002)$ & $(0.005)$ & $(0.003)$ & $(0.002)$ & $(0.002)$ & $(0.005)$ \\
\hline \multirow[t]{2}{*}{ Tenure 1-2 years } & -0.226 & -0.158 & -0.105 & -0.059 & -0.013 & -0.134 & -0.070 & -0.027 & 0.007 & 0.047 \\
\hline & $(0.002)$ & $(0.001)$ & $(0.001)$ & $(0.001)$ & $(0.002)$ & $(0.047)$ & $(0.002)$ & $(0.002)$ & $(0.002)$ & $(0.005)$ \\
\hline \multirow[t]{2}{*}{ Tenure 2-4 years } & -0.156 & -0.115 & -0.081 & -0.050 & -0.018 & -0.087 & -0.047 & -0.018 & 0.005 & 0.030 \\
\hline & $(0.002)$ & $(0.001)$ & $(0.001)$ & $(0.001)$ & $(0.002)$ & $(0.004)$ & $(0.002)$ & $(0.002)$ & $(0.002)$ & $(0.004)$ \\
\hline \multirow[t]{2}{*}{ Tenure 4-7 years } & -0.098 & -0.075 & -0.055 & -0.036 & -0.019 & -0.058 & -0.034 & -0.015 & 0.000 & 0.013 \\
\hline & $(0.002)$ & $(0.001)$ & $(0.001)$ & $(0.001)$ & $(0.002)$ & $(0.004)$ & $(0.002)$ & $(0.002)$ & $(0.002)$ & $(0.004)$ \\
\hline \multirow[t]{2}{*}{ Tenure $7-15$ years } & -0.096 & -0.090 & -0.094 & -0.092 & -0.080 & -0.032 & -0.030 & -0.017 & -0.018 & -0.032 \\
\hline & $(0.003)$ & $(0.002)$ & $(0.002)$ & $(0.002)$ & $(0.004)$ & $(0.005)$ & $(0.004)$ & $(0.004)$ & $(0.005)$ & $(0.008)$ \\
\hline \multirow[t]{2}{*}{ Part-time } & 0.034 & 0.146 & 0.274 & 0.412 & 0.529 & 0.031 & 0.081 & 0.173 & 0.306 & 0.384 \\
\hline & $(0.002)$ & $(0.001)$ & $(0.001)$ & $(0.001)$ & $(0.002)$ & $(0.006)$ & $(0.003)$ & $(0.003)$ & $(0.003)$ & $(0.006)$ \\
\hline Temporary & -0.003 & 0.015 & 0.030 & 0.052 & 0.077 & -0.126 & -0.081 & -0.049 & -0.019 & 0.016 \\
\hline & $(0.001)$ & $(0.001)$ & $(0.000)$ & $(0.001)$ & $(0.001)$ & $(0.003)$ & $(0.001)$ & $(0.001)$ & $(0.001)$ & $(0.003)$ \\
\hline Size $<10$ employees & -0.123 & -0.104 & -0.096 & -0.090 & -0.073 & -0.044 & -0.038 & -0.038 & -0.036 & -0.031 \\
\hline & $(0.001)$ & $(0.001)$ & $(0.000)$ & $(0.001)$ & $(0.001)$ & $(0.003)$ & $(0.002)$ & $(0.001)$ & $(0.002)$ & $(0.003)$ \\
\hline Size 10-50 employees & -0.086 & -0.079 & -0.076 & -0.073 & -0.066 & -0.032 & -0.029 & -0.025 & -0.020 & -0.012 \\
\hline & $(0.001)$ & $(0.001)$ & $(0.000)$ & $(0.001)$ & $(0.001)$ & $(0.003)$ & $(0.002)$ & $(0.001)$ & $(0.001)$ & $(0.003)$ \\
\hline Size 50-200 employees & -0.045 & -0.033 & -0.023 & -0.016 & -0.010 & -0.026 & -0.017 & -0.010 & -0.004 & 0.002 \\
\hline & $(0.002)$ & $(0.001)$ & $(0.001)$ & $(0.001)$ & $(0.002)$ & $(0.004)$ & $(0.002)$ & $(0.001)$ & $(0.002)$ & $(0.004)$ \\
\hline Constant & 1.564 & 1.682 & 1.715 & 1.728 & 1.749 & 1.377 & 1.512 & 1.602 & 1.687 & 1.854 \\
\hline & $(0.010)$ & $(0.005)$ & $(0.004)$ & $(0.005)$ & $(0.009)$ & $(0.026)$ & $(0.014)$ & $(0.011)$ & $(0.014)$ & $(0.027)$ \\
\hline Pseudo R-squared & 0.178 & 0.174 & 0.186 & 0.182 & 0.166 & 0.301 & 0.291 & 0.281 & 0.256 & 0.239 \\
\hline Joint p-value & 0.00 & 0.00 & 0.00 & 0.00 & 0.00 & & & & & \\
\hline & & & & & & & & & & \\
\hline
\end{tabular}


Table B.4: Quantile regression estimates for public and private sectors - Women

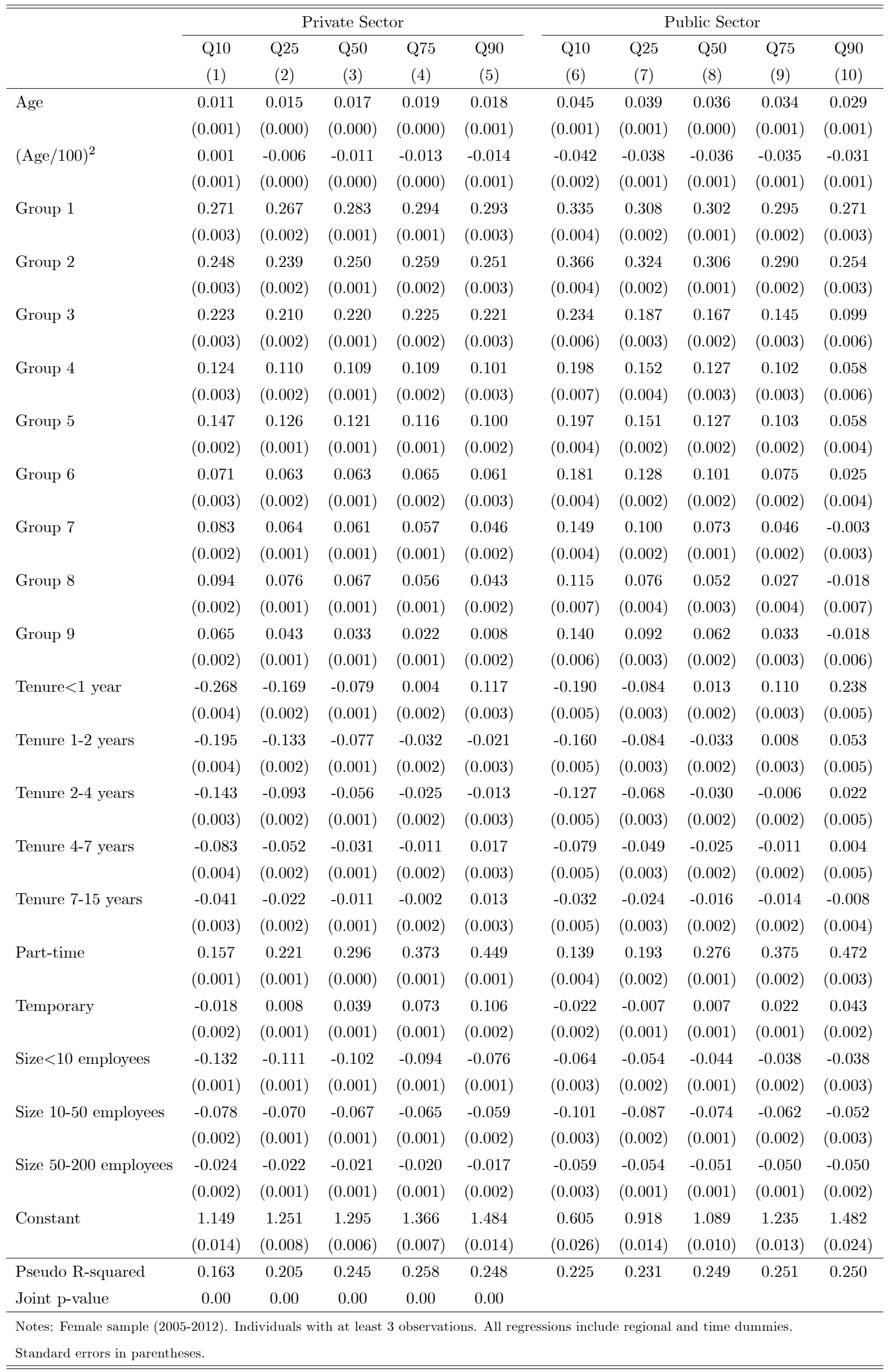

